\title{
Alguns Crinoides da Formação Ponta Grossa e suas afinidades paleobiogeográficas (Devoniano Inferior, Bacia do Paraná, Brasil)
}

\author{
Some Crinoids of the Ponta Grossa Formation and \\ paleobiogeographic affinities (Early Devonian, Parana Basin,
Brazil) \\ paleobiogeographic affinities (Early Devonian, Parana Basin,
Brazil)
}

\author{
Sandro Marcelo Scheffler \\ schefflersm@gmail.com \\ Universidade Federal de São Paulo \\ Antonio Carlos Sequeira Fernandes \\ fernande@acd.ufrj.br \\ Universidade Federal do Rio de Janeiro \\ Vera Maria Medina da Fonseca \\ vmmedinafonseca@gmail.com \\ Universidade Federal do Rio de Janeiro
}

\begin{abstract}
Resumo: A primeira descrição e ilustração de equinodermas da Formação Ponta Grossa foi apresentada por John Mason Clarke, na Monografia número 1 do Serviço Geológico e Mineralógico do Brasil, na qual descreveu duas espécies de estrelas-do-mar, únicos asterozoários ainda hoje conhecidos nessa unidade. Nesse trabalho, também foi apresentada uma das primeiras descrições de crinoides da América do Sul, com base em material das Ilhas Malvinas. Em todo o restante do século XX, poucos foram os trabalhos que versaram sobre os equinodermas do Devoniano da Bacia do Paraná, resultando em um conhecimento parco de sua fauna. O presente estudo pretende dar continuidade ao esforço iniciado por Clarke no estudo do filo, apresentando a identificação e a descrição de quatro formas de crinoides para a Formação Ponta Grossa: Ophiocrinus stangeri, Monobathrida indet., Ctenocrinus sp. e Costalocrinus? sp. As afinidades paleobiogeográficas da fauna de equinodermas da América do Sul são discutidas, e curiosamente, poucos são os táxons em comum entre os vários países que formavam o Domínio Malvinocáfrico. Essa fauna parece apresentar grande influência das formas do Maciço Xistoso Renano (sul da Báltica), Maciço Armoricano e Península Ibérica (Armórica) e norte da África (norte do Gondwana).
\end{abstract}

Palavras Chaves: Crinoidea. Taxonomia. Praguiano. Emsiano. América do Sul.

\begin{abstract}
The first description and illustration of the echinoderms from Ponta Grossa Formation was presented by John Mason Clarke, in the first Monograph of the Geological and Mineralogical Survey of Brazil. In this work, he describes two species of starfish, the only asterozoans still known in this geological unit. Clarke also presents one of the first descriptions of crinoids in South America, based on material of the
\end{abstract}


Falkland Islands. Throughout the remainder of the twentieth century, few works were published about the devonian echinoderms of the Paraná Basin, resulting in a meager knowledge of this Filo. This paper intends to continue the effort initiated by Clarke, with the identification and description of four forms of the crinoids from Ponta Grossa Formation: Ophiocrinus stangeri, Monobathrida indet., Ctenocrinus sp., and Costalocrinus? sp. The affinities paleobiogeographic of the fauna of echinoderms from South America are discussed, and interestingly, there are few taxa in common between the various countries that formed the Malvinokaffric Realm. This fauna seems to have great influence of the taxons from the Rhenish Schist Massif (southern Baltica), Armorican Massif and the Iberian Peninsula (Armorica) and North of the Africa (northern Gondwana).

Keywords: Crinoidea. Taxonomy. Praguian. Emsian. South America.

\section{INTRODUÇÃO}

A primeira ocorrência de equinodermas na Bacia do Paraná foi realizada por Orville Adelbert Derby, quando publicou suas primeiras observações sobre a presença de rochas devonianas no estado do Paraná (ver SCHEFFLER, 2007). Nesse trabalho, Derby (1878, p. 93) apresentou uma listagem de fósseis coletados por ele nas localidades descobertas em 1876 por Luthero Wagoner, integrante da antiga Comissão Geológica do Império: “[...] foram encontrados uma espécie de Ophiuraneos, alguns mal preservados Lamellibranchios e espécies de Lingula, Discina, Spirifer, Rhynchonella, Streptorhynchus e Vitulina..." (grifo nosso).

Esta representa a segunda citação do filo para o Brasil, antecipada somente pela citação de Hartt \& Rathbun (1875) para o Devoniano da Bacia do Amazonas. Esse material foi posteriormente descrito e identificado por John Mason Clarke em sua célebre monografia do Serviço Geológico e Mineralógico do Brasil, homenageada neste volume especial. Clarke (1913) descreveu pela primeira vez para o Paleozoico da América do Sul espécies da classe Asteroide, identificadas como Aspidossoma? pontis (posteriormente renomeado como Encrinaster pontis e considerado atualmente como um ofiuroide) e Echinasterella? darwini.

Clarke também incluiu em sua monografia uma das primeiras descrições ilustradas da classe Crinoidea para a América do Sul, realizadas por Kirk (1913) com base em material do Devoniano das Ilhas Malvinas, identificado como Botryocrinus doubleti (posteriormente renomeado por McIntosh,1983, com Pyrenocrinus? doubleti).

O significado desse trabalho para o estudo dos equinodermas no Devoniano da Bacia do Paraná pode ser vislumbrado quando observamos que se trata de uma das poucas identificações realizadas ao longo de todo o século $X X$, sendo acompanhadas apenas pelas identificações dos homalozoários paranaenses por Caster (1954a, b). Além desses três trabalhos, apenas algumas resumidas descrições e citações foram realizadas (e.g. LANGE, 1943; FERREIRA \& FERNANDES, 1985). A partir do século XXI, os trabalhos com o filo foram intensificados na Formação Ponta Grossa (SCHEFFLER et al., 2002; SCHEFFLER \& FERNANDES, 2007a,b; SCHEFFLER, 2008); no entanto, o conhecimento do grupo ainda é considerado limitado. 
O objetivo deste artigo é dar continuidade ao trabalho com esse filo iniciado na Formação Ponta Grossa por Clarke (1913), apresentando a descrição e a identificação de quatro coroas de crinoides, sendo duas delas correspondentes a uma revisão da identificação anteriormente apresentada em Scheffler \& Fernandes (2007a): Ophiocrinus stangeri, uma típica espécie malvinocáfrica e Monobathrida indet., Ctenocrinus sp. e Costalocrinus? sp., as primeiras citações confirmadas da ordem e dos gêneros para o Brasil. Além disso, também é apresentada uma listagem dos crinoides devonianos da América do Sul e são discutidas as suas afinidades paleobiogeográficas.

\section{CARACTERIZAÇÃO DA ÁREA E MATERIAL DE ESTUDO}

Os estratos do Devoniano da Bacia do Paraná são representados pelos sedimentos das formações Furnas, Ponta Grossa e São Domingos (sensu GRAHN et al., 2012; BOSETTI et al., 2012) e estão incluídos no registro estratigráfico em uma unidade de ampla escala (Supersequência Paraná sensu MILANI et al., 2007). Esses estratos se caracterizam por condições marinhas representadas por sucessões sedimentares que definem ciclos transgressivo-regressivos ligados a oscilações do nível relativo do mar.

As 14 amostras aqui analisadas procedem de afloramentos que apresentam sedimentos de idade Praguiana/Emsiana pertencentes à Formação Ponta Grossa, no estado do Paraná:

- Afloramento Jaguariaíva: corte do ramal ferroviário de Jaguariaíva-Arapoti, $\mathrm{Km} 3,0$ (amostra CPg004a), Km 3,9 (amostras CT001, CT047, СT076B, СT082, СT087, СТ088) e Km 4,4 (amostras CT081 (A-B), CT046 (A-B)), município de Jaguariaíva. Este é o afloramento tipo do Membro Jaguariaíva e está posicionado no Praguiano de acordo com Grahn (1999).

- Localidade incerta: possivelmente Formação Ponta Grossa (amostras UEPG-MPI-1473).

- Afloramento Cerâmica Sul-Brasil: município de Ponta Grossa, na área da pedreira da extinta cerâmica, fundos da Vila Ricci, próximo ao conjunto habitacional Santa Paula (amostra MCN. P. 425). Por localização geográfica sua idade possivelmente corresponde ao Praguiano-Emsiano.

- Afloramento Curva do Trilho II: corte de estrada de ferro Central do Paraná, trecho Uvaranas-Apucarana, sub-trecho Uvaranas-Periquitos, aproximadamente $2 \mathrm{~km}$ a frente do afloramento Curva do Trilho I, na próxima curva da ferrovia, município de Ponta Grossa (UNIRIO-29EQ UNIRIO-76EQ, UNIRIO-77EQ). A análise da lâmina CB-Z00906214-1 e CB-Z00906215-1 do Cenpes/Petrobras, realizada por José Henrique Gonçalves de Mello indicou biozona indeterminada, de provável idade eodevoniana (pré-neopraguiana). 
Figura 1. Área de exposição das rochas do Grupo Campos Gerais no estado do Paraná, apresentando a localização dos afloramentos estudados (modificado de Bosetti et al., 2012)

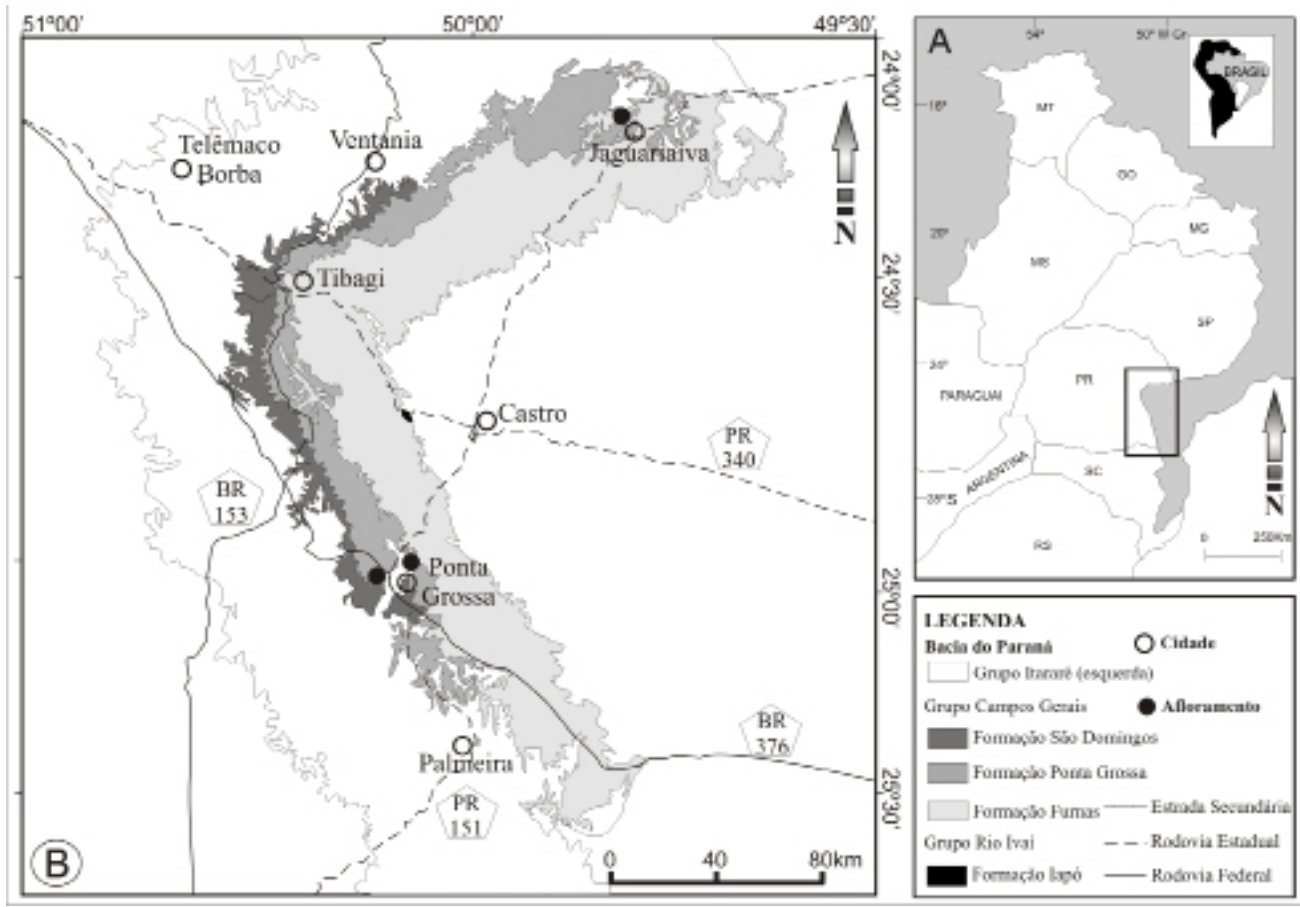

O material analisado encontra-se depositado nas seguintes coleções de paleontologia: Departamento de Geologia da Universidade Federal do Paraná (CT), Curitiba; Laboratório de Geociências, Universidade de Guarulhos (CPg), Guarulhos; Unidade de Paleontologia, Museu de Ciências Naturais, Setor de Ciências Biológicas, Universidade Federal do Paraná (MCN.P.), Curitiba; Departamento de Geografia, Universidade Estadual de Ponta Grossa (UEPG-MPI), Ponta Grossa; e Laboratório de Estudos de Comunidades Paleozoicas, Universidade Federal do Estado do Rio de Janeiro (UNIRIO), Rio de Janeiro.

\section{SISTEMÁTICA PALEONTOLÓGICA}

A análise morfológica dos crinoides seguiu Ubaghs (1978a) e, sempre que possível, o sistema apresentado por Fearnhead (2008); a taxonomia seguiu aquela apresentada no Treatise on Invertebrate Paelontology (UBAGHS, 1978b; MOORE et al., 1978, modificada por trabalhos posteriores).

Filo ECHINODERMATA Klein, 1734

Classe CRINOIDEA Miller, 1821

SubClasse CAMERATA Wachsmuth \& Springer, 1885

Ordem DIPLOBATHRIDA Moore \& Laudon, 1943

SuperFamília RHODOCRINITACEA Roemer, 1855 
Família OPSIOCRINIDAE Kier, 1952

Gênero Ophiocrinus Salter, 1856

Ophiocrinus stangeri Salter, 1856

(Figuras 3A-D)

Cálice de crinoide, Scheffler \& Fernandes, 2003, p. 258-259.

Ophiucrinus stangeri, Scheffler, 2004b, p. 125-131, estampa 1 figs 1-4.

Ophiucrinus stangeri, Scheffler \& Fernandes, 2007a, p. 86 - 89, figs. 3 e 4.

Ophiocrinus stangeri, Scheffler, 2010, p. 154-158, fig-text. 46, estampa 12, figuras 1-4.

Espécie-tipo: Ophiocrinus stangeri Salter, 1856.

Material:CT001, СT047, СT076B, СТ082, СT087, СT088.

Procedência: Afloramento Jaguariaíva, Km 3,9 da estrada de ferro.

Descrição1: Copo dorsal globoso de pequena altura (CT 001, diâmetro: 1,8 mm; altura: 1,4 mm). Cálice criptodicíclico. Basais em número de cinco, hexagonais, mais largas que altas, com maior largura na metade aboral (o espécimen da amostra CT 001 apresenta duas basais; altura: 2,4-2,5 mm e largura: 2,8-3,0 mm). Radiais em número de cinco, pentagonais, tão altas quanto largas, com maior largura na metade aboral; radiais separadas entre si, penetrando profundamente entre o circuito das basais (figuras 2, 3C, 3D). Primeiras primibraquiais hexagonais; segundas primibraquiais axilares, pentagonais; primeiras secundibraquiais retangulares, segundas secundibraquiais axilares, pentagonais; primeiras tertibraquiais retangulares fixas e demais tertibraquiais livres. Vinte braços livres não ramificados, pinulados, unisseriados na região proximal, com braquiais retangulares que se tornam progressivamente mais cuneadas para a região distal (figuras 3A, 3Aa, 3B). Áreas interbraquiais amplas e deprimidas. Interprimibraquiais numerosas (entre 25 e 30 placas); primeira interprimibraquial hexagonal em contato com a basal e radiais adjacentes; segunda linha com três interprimibraquiais; terceira linha com quatro interprimibraquiais; demais linhas com três ou quatro interprimibraquiais. Intersecundibraquiais numerosas (entre 10 e 15 placas), pequenas e poligonais. Pedúnculo circular, heteromórfico; nudinodais com grande epifaceta; superfície articular finamente crenulada e aréola grande.

Discussão: O material aqui descrito apresenta afinidade com as espécies Ophiocrinus stangeri Salter, 1856 e Ophiocrinus (Opsiocrinus) mariae Jell \& Theron, 1999, que constituem as únicas espécies desse gênero. As duas espécies ocorrem no Devoniano Inferior da Série Bokkeveld da África do Sul, sendo que O. mariae também ocorre no Devoniano da América do Norte; esse gênero também foi citado por Jell \& Theron (1999) para o Devoniano da Austrália. O. mariae difere do material da Formação Ponta Grossa por possuir dez braços, pelas áreas interbraquiais menos amplas e mais deprimidas, pelas placas interbraquiais possuírem ornamentação, pelas suturas entre as placas do cálice serem profundamente

${ }^{1}$ Para descrição e discussão completa ver Scheffler \& Fernandes (2007a) e Scheffler (2010). 
deprimidas e por apresentarem infrabasais visíveis lateralmente (JELL \& THERON, 1999). O material paranaense foi, portanto, identificado como O. stangeri, pertencendo provavelmente a uma população dessa espécie que resguarda características mais basais em relação às tendências evolutivas da Classe Camerata (principalmente pela ausência de contato entre as primeiras interprimibraquiais com as primeiras primibraquiais, pelo maior número de placas na segunda fileira de interprimibraquiais e nas áreas interbraquiais como um todo, e pela primeira tertibraquial parcialmente fixa).

Figura 2. À esquerda, desenho esquemático mostrando a distribuição das placas dos espécimens de Ophiocrinus stangeri da África do Sul (modificado de Jell \& Theron, 1999). À direita, ilustração do holótipo de Ophiocrinus stangeri (modificada de Salter, 1856)

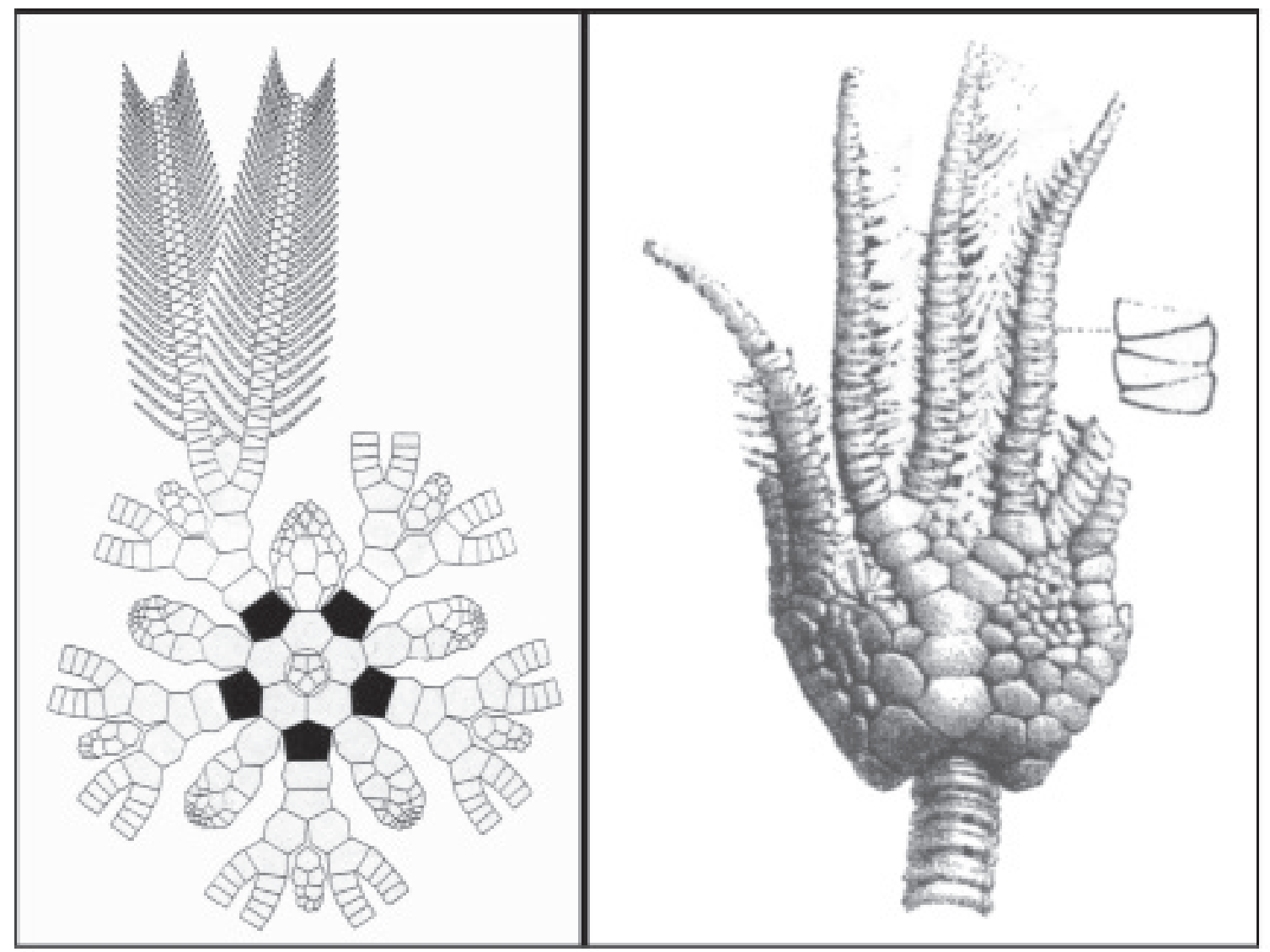

Observações: As medidas da descrição são do espécimen da amostra CT 001, com exceção do comprimento dos braços, que é do espécimen da amostra CT 047. No mesmo nível de ocorrência do material aqui descrito, foram encontradas amostras que apresentam outro cálice com fragmento de pedúnculo articulado e diversos braços, nas quais é possível visualizar o mesmo padrão morfológico dos braços de O. stangeri (CT 076B, CT 082, CT 087, CT 088), sendo, provavelmente, indivíduos dessa espécie. Nesses braços, as braquiais são em forma de cunha; pínulas presentes em todas as braquiais, sendo as pinulares mais altas que largas; sulco adoral bem desenvolvido, como descrito por Jell \& 
Theron (1999) para os exemplares de O. stangeri da África do Sul; e articulação simplectial entre as braquiais, possuindo em torno de 20 crênulas. Nas mesmas amostras ocorre o Morfotipo PRap/PG-001 (SCHEFFLER, 2008), que possivelmente representa o pedúnculo dessa espécie.

Figura 3. A-D: Ophiocrinus stangeri, A - cálice em vista lateral apresentando fragmentos de braços de dois raios (CT047), R - radiais, B - basais, IIBrr - secundibraquiais; Aa - desenho esquemático mostrando a disposição dos raios da figura anterior (CT047); B - fragmento de braço apresentando as braquiais em forma de cunha com pínulas articuladas (CT082B); C - cálice em vista lateral (CT001); D - detalhe da figura anterior (CT001). E - I: Monobathrida indet., E - vista geral de cálice e braços de dois raios (UEPGMPI-1473); F - ampliação do copo dorsal; G - outra vista do copo dorsal e parte inicial dos braços; H detalhe da parte distal do braço unisseriado, mostrando as braquiais em forma de cunha portando pínulas com longas pinulares; I - detalhe da parte proximal do braço unisseriado, com braquiais quadrangulares assumindo rapidamente leve forma de cunha; $\mathbf{J}$ - vista geral do único braço completo

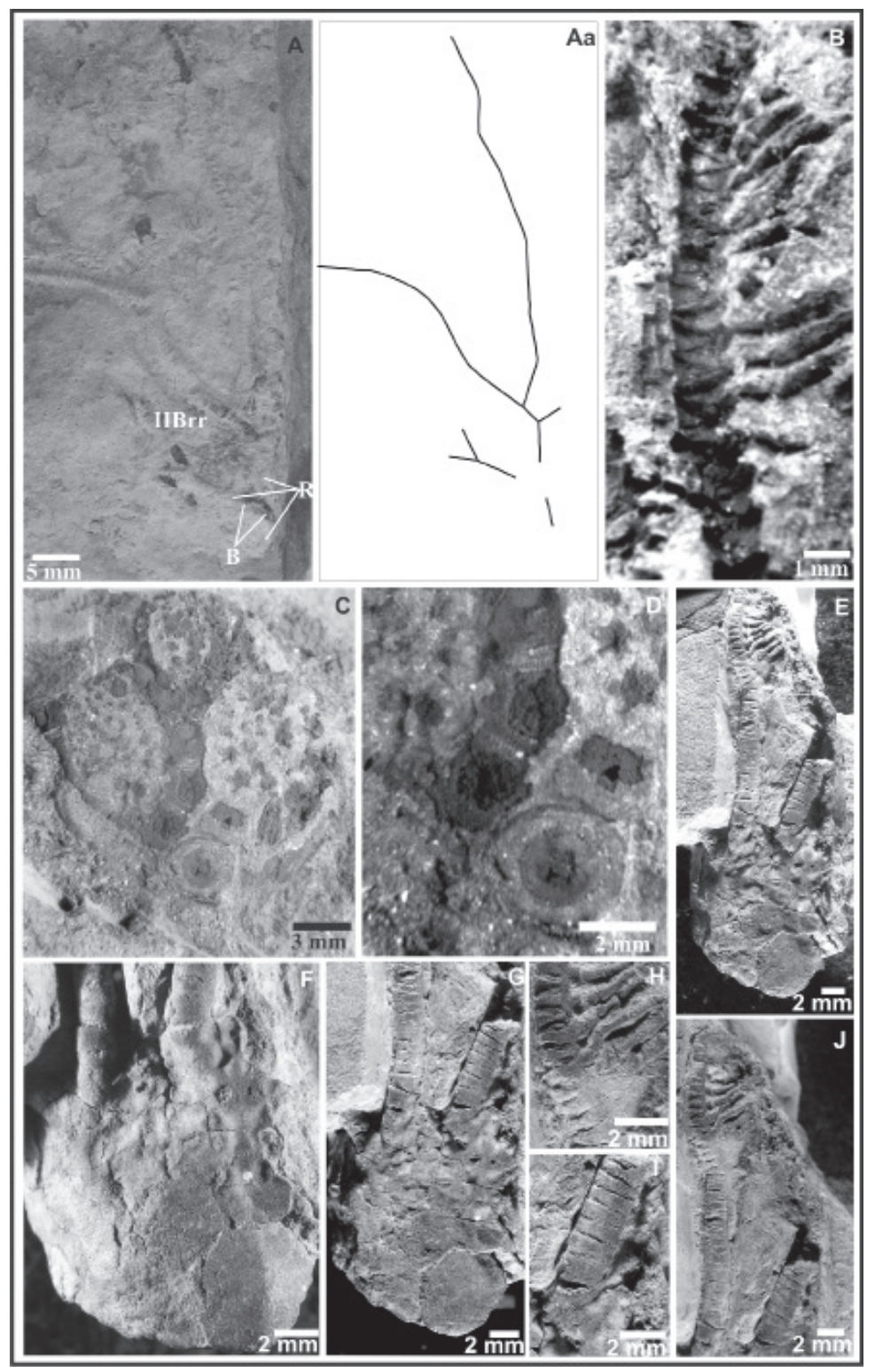


Distribuição Cronoestratigráfica e Geográfica. Devoniano Inicial (Emsiano) da Série Bokkeveld da África do Sul e Devoniano Inicial (Praguiano) da Formação Ponta Grossa (Grupo Paraná) da América do Sul.

Ordem MONOBATHRIDA Moore \& Laudon, 1943

Monobathrida indet.

(Figuras 3E-I, 4)

Dimerocrinitidae? Indet., Scheffler, 2010, p. 158-160, fig-text. 47, estampa 12, figuras 5-10.

Material: UEPG-MPI-1473.

Procedência: Formação Ponta Grossa, localidade incerta.

Unidade litoestratigráfica: Formação Ponta Grossa, Devoniano.

Descrição: Fragmento de crinoide, bastante compactado, apresentando o cálice preservado acima da radial (cálice acima das basais com 1,7 cm de altura). Radiais grandes em número de cinco (figuras 3E, F, G), provavelmente heptagonais, que não se inserem profundamente entre as basais e estão unidas umas as outras (radial incompleta com 6,2 mm de altura por 7,4 $\mathrm{mm}$ de largura). Cada radial sustenta duas primibraquiais hexagonais, mais largas que altas, com maior altura acima da metade da altura (figura 4). Terceira primibraquial axilar, pentagonal a heptagonal. Presença de leve crista mediana que parte do centro das radiais e percorre as primibraquiais, bifurcando-se sobre a axilar. Primeira e segunda secundibraquiais fixas, sendo o restante dos braços livres. Inter-raios compostos por várias placas poligonais, bem organizadas, deprimido em relação aos raios. Primeira interprimibraquial hexagonal, em contato com duas radiais adjacentes e com a primeira primibraquial dos dois raios adjacentes. Segunda linha de priminterbraquiais formada por duas placas; terceira linha com três placas situadas na altura das primaxilares; quarta linha aparentemente com duas placas?, em contato com as secundibraquiais. Inter-raio em contato com o tegmen, maior largura do priminterraio situada na altura do contato entre a segunda primibraquial e a primaxilar. Apenas uma placa intersecundibraquial visível, mais alta que larga. Dois braços livres por raio a partir da terceira secundibraquial. Braquiais livres gradativamente se tornam mais cuneadas distalmente, porém os braços permanecem unisseriados, pinulados e simples (figura 3I, J). Pínulas com pinulares longelíneas, bem mais longas que largas (figura $3 \mathrm{H}$ ). Maior comprimento de braço livre observado de aproximadamente quatro centímetros. Não é possível dizer se o inter-raio CD é diferenciado, pois nem todos os inter-raios estão bem preservados. Sutura das braquiais simplectial, com crenulação média. 
Figura 4. Esquema da disposição das placas do cálice e parte proximal dos braços em Monobathrida indet. $\mathrm{R}$ - radial, $\mathrm{Br}$ - braquial, $\mathrm{IBr}$ - priminterbraquial

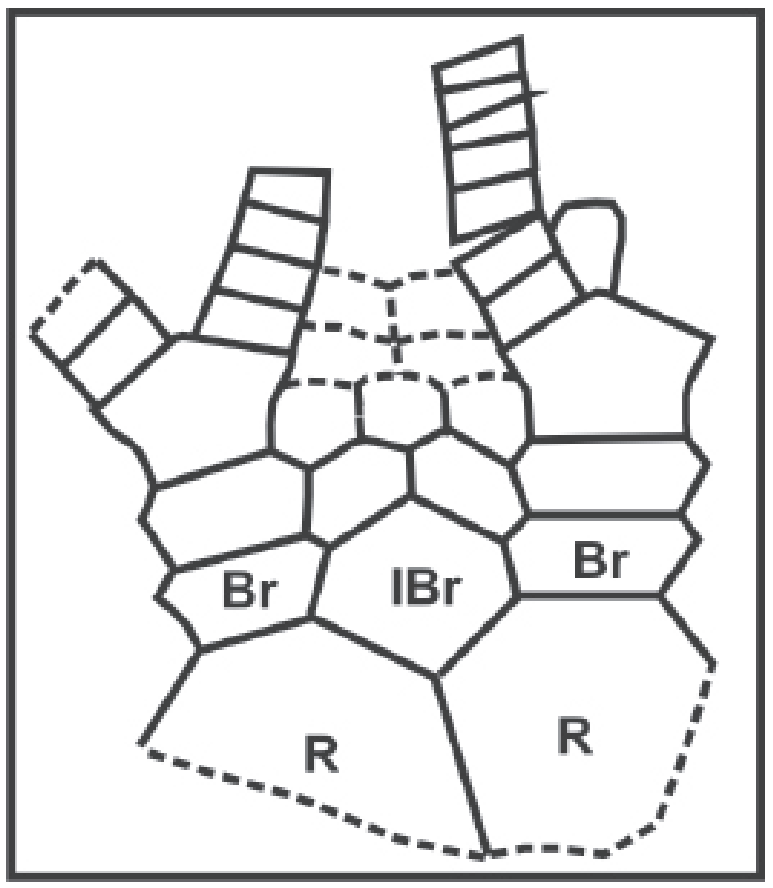

Discussão: A radial heptagonal, primibraquial hexagonal e a morfologia dos braços e pínulas se assemelha ao Camerata monocíclico indet. descrito por Jell \& Theron (1999) para o Devoniano da África do Sul. Estes comentaram que a grande radial sugere afinidade com o grupo dos Compsocrininae avançados e que há grande similaridade com os espécimes do gênero Acacocrinus. Monbathrida Indet difere do Camerata monocíclico indet. por apresentar a terceira primibraquial axilar ao invés da segunda. Apesar das semelhanças, não é possível refinar o posicionamento sistemático desse espécimen e o encontro de material adicional é necessário para uma descrição mais completa.

Subordem GLYPTOCRININA Moore, 1952

Superfamília MELOCRINITACEA d'Orbigny, 1852

Family MELOCRINITIDAE d'Orbigny, 1852

Gênero Ctenocrinus Bronn, 1840

Ctenocrinus sp.

(figura 5A-L)

Cálice de Crinoidea, Scheffler et al., 2001, p. 11.

Poteriocrinida indet., Scheffler, 2004b, p. 103-131, Estampa 2, figs. 1-4.

Poteriocrinida indet., Scheffler \& Fernandes, 2007a, p. 89-90, fig. 5.

Poteriocrinida indet., Scheffler, 2010, p. 170-171, estampa 14, figuras 13-15.

Espécie-tipo: Ctenocrinus typus Bronn, 1840

Material: MCN. P. 425 


\section{Procedência: Afloramento Cerâmica Sul-Brasil}

Unidade litoestratigráfica: Provavelmente base da Formação Ponta Grossa, idade Praguiana-Emsiana?

Descrição: Crinoide relativamente grande com diâmetro observado incompleto da coroa de $11 \mathrm{~cm}$, apresentando cinco "raios troncos" ou ramos principais dispostos radialmente, não bifurcados, com râmulas não pinuladas, bisseriadas, a cada três braquiais em cada ramo (figuras $5 \mathrm{~A}-\mathrm{C}$ ). Os ramos estão posicionados com a superfície oral voltada para cima (diâmetro do ramo principal: $6 \mathrm{~mm}$; comprimento máximo de braço observado: 55 $\mathrm{mm}$ ). Braquiais do ramo principal de pequena altura, retangulares em vista longitudinal (altura da braquial: $1 \mathrm{~mm}$ ); râmulas bisseriadas com sutura em forma de zigue-zague (figura $5 \mathrm{~F}$ ), diminuindo em comprimento em direção à extremidade do braço (diâmetro na base: 0,15 mm; máximo comprimento observado: $25 \mathrm{~mm}$ ); ramo principal com canal ambulacral largo $(0,75 \mathrm{~mm}$ a $1 \mathrm{~mm})$; pódios podem ser visualizados tanto no canal ambulacral do ramo principal quanto nas râmulas (figuras $5 \mathrm{E}, \mathrm{G}-\mathrm{K}$ ); râmulas distais possuem em torno de 30 pódios (comprimento dos pódios: 0,65 $\mathrm{mm}$ ).

Discussão. Os braços formados por raios troncos são típicos de um Melocrinitidae, que foi atribuído a Ctenocrinus por não apresentar ramos externos bem desenvolvidos e pela presença de râmulas bisseriadas, com ausência de pínulas. Apesar de existir espécies de Ctenocrinus com râmulas unisseriadas, como C. pauchyidactylus do Devoniano Inferior de Nova Iorque, suas râmulas partem do raio tronco a cada cinco a nove braquiais. Esse complexo sistema de coleta de comida possibilitou que esses crinoides atingissem grandes tamanhos (BROWER, 1974). Conforme Thompson et al., (2013), o gênero é amplamente conhecido do Siluriano médio (Wenlockoviano) até o Devoniano Tardio (Frasniano) da Europa; do Siluriano médio (Niagarano) ao Devoniano Inferior (Helderbergiano dos Estados Unidos); do Devoniano Inferior (Lochkoviano) da Austrália; do Devoniano Inferior (Emsiano) da Bolívia; e agora do Devoniano Inferior (Praguiano-Emsiano?) do Brasil. Até 2013, o gênero havia sido citado para a América do Sul somente com base em pluricolunais e colunais isoladas por Boucot (1971) para o Devoniano do Paraguai (Ctenocrinus? sp. indet.) por Ulrich (1892), que argumentou que alguns fragmentos de pedúnculos do Devoniano da Bolívia poderiam ser atribuídos ao gênero Ctenocrinus, material posteriormente chamado por Knod (1908) de Ctenocrinus sp., e por Katzer $(1903,1933)$ para o Devoniano da Bacia do Amazonas (Ctenocrinus sp.), sendo que Lange (1943) chamou a atenção para a semelhança de fragmentos de pedúnculo do Paraná com os espécimens de Knod (1908). Os espécimens descritos e ilustrados por Katzer $(1903,1933)$ hoje são identificados como Laudonomphalus regularis (SCHEFFLER et al., 2006; para a Formação Maecuru) e Botryocrinus meloi (SCHEFFLER et al., 2013, no prelo; para a Formação Ererê), assim como é possível atribuir ao menos um espécimen de Knod (1908, pl. XXIX, fig. 8) a Laudonomphalus regularis e outro possivelmente a Botryocrinus? sp. (Knod, 1908, pl. XXIX, fig. 7). Os espécimens descritos por Lange (1943) muito provavelmente também não pertencem a esse gênero. Portanto, as ocorrências anteriores a 2013 ou são todas atribuídas atualmente a outros gêneros ou são duvidosas, sendo que as únicas ocorrências com base em cálices do gênero, e portanto mais precisas, para a América do Sul, são de Ctenocrinus 
branisai (Thompson et al., 2013) para o Emsiano da Bolívia (Formação Belén) e a presente descrição. O padrão de ramulação dos raios troncos se assemelha muito a $C$. typus, do Devoniano Inferior (Siegeniano) da Alemanha, ilustrada no Treatise Invertebrate Paleontology (UBAGHS, 1978b); no entanto, também se assemelha a C. branisai, espécie descrita e ilustrada por Thompson et al. (2013) para o Emsiano da Bolívia. Foram recentemente realizadas tentativas de visualizar o cálice encoberto por sedimento através de exames por raios-X (com diversas intensidades de radiação e para diferentes densidades de sedimento) e por tomografia computadorizada (com diversos filtros de partes moles e de ossos), pois é muito improvável sua remoção sem danificar o espécimen. Infelizmente, só foi possível confirmar a presença do cálice, sem, no entanto, esclarecer mais sobre sua morfologia. Notável nesse espécimen é a preservação de partes moles e extremamente delicadas como os pódios, estruturas constituídas por uma fina camada de epiderme e derme que têm funções principais da captura e transporte de alimento e trocas gasosas (figuras 5G-K). Conforme Ausich et al. (2013), a preservação de tecidos moles em equinodermas é extremamente rara, sendo que a maioria das comunicações tem sido refutada. De acordo com Ausich et al. (2013), existem apenas três registros confirmados de pódios em ofiuroides e um em asteroides, além de dois para crinoides (SCHEFFLER \& FERNANDES, 2007a; AUSICH et al., 2013). Portanto, neste trabalho, é confirmada a primeira publicação de ocorrência de pódios ou pés ambulacrais em crinoides, realizada anteriormente por SCHEFFLER \& FERNANDES (2007a) para o espécime aqui identificado. Curiosamente, as duas ocorrências de pódios são do Devoniano, sendo que o material de Ausich et al. (2013) se refere a Codiacrinus schultzei do Devoniano Inferior do Maciço Renano da Alemanha. Uma pluricolunal (MCN.P.164, figuras 5D, L) apresenta um grande pedúnculo heteromórfico, incomum na Formação Ponta Grossa, noditaxe com quatro colunais, látera lisa e levemente convexa e nodal com látera com leve quilha abaixo da meia altura (altura da nodal - $1 \mathrm{~mm}$; diâmetro da nodal $-7,8 \mathrm{~mm}$; altura do noditaxe -3 $\mathrm{mm}$ ). Esse padrão morfológico é típico de Ctenocrinus, no entanto, a ausência de faceta articular preservada impossibilita a atribuição com certeza ao gênero. 
Figuras 5. Ctenocrinus sp.: A - vista geral da amostra apresentando cinco raios tronco dispostos radialmente com a superfície oral voltada para cima (MCN. P. 425); B - detalhe do ramo principal (esquerdo superior da figura anterior) mostrando o padrão unisserial; C - mesmo raio da figura anterior; D - detalhe do pedúnculo apresentado na figura 5L; E - ramo principal com râmulas apresentando pódios (raio inferior da figura 5A, setas indicam posição dos pódios das figuras 5I- K); F - detalhe da figura 5B apresentando as râmulas bisseriadas; G - maior aumento das três râmulas superiores da figura 5E (notar a impressão dos pódios do canal ambulacral preservada na parte inferior da figura); $\mathbf{H}$ - maior aumento da figura anterior; I-K - pódios preservados; L - possível pedúnculo de Ctenocrinus sp.

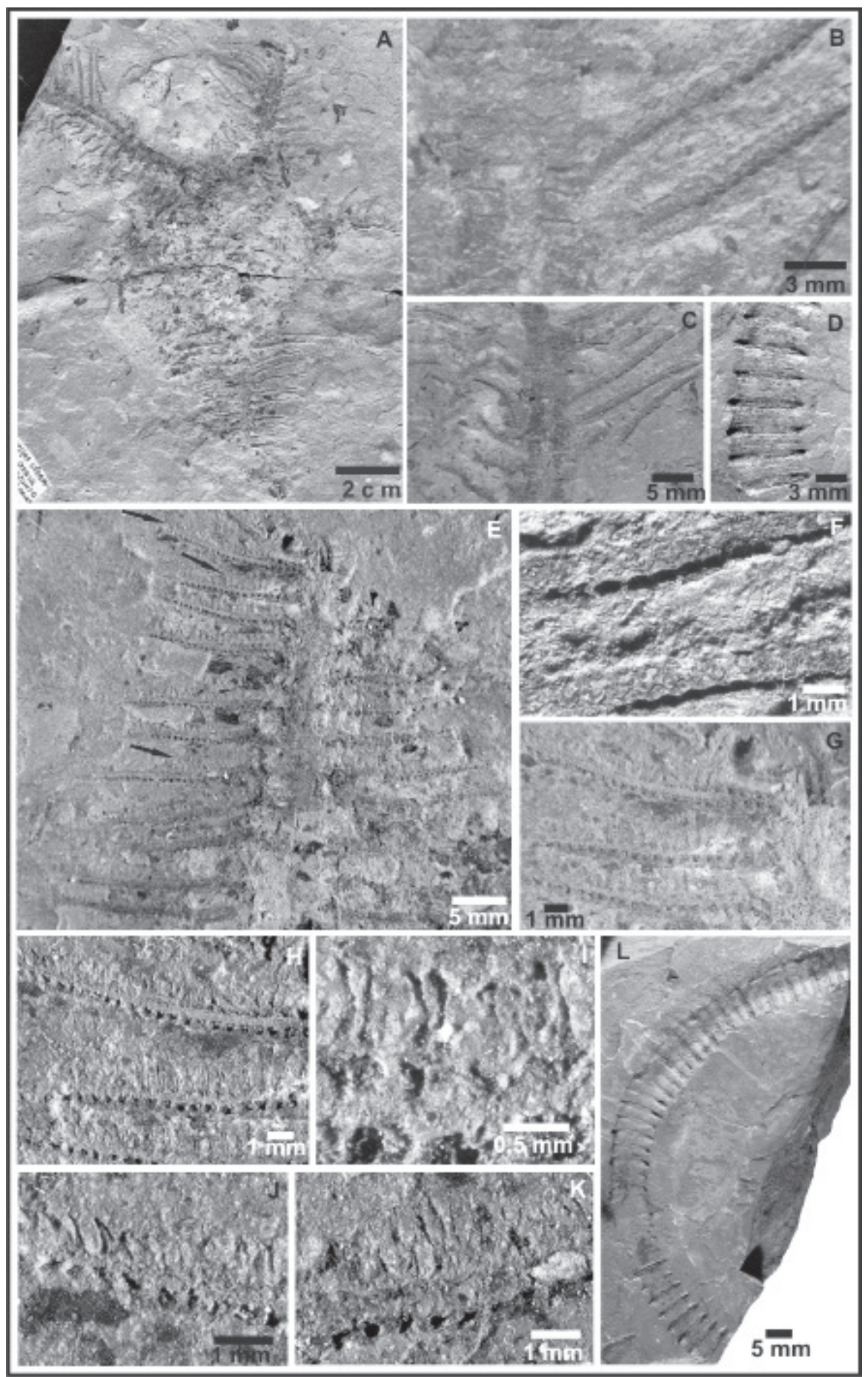


Sub-Classe CLADIDA Moore \& Laundon, 1943

Ordem DENDROCRINIDA Bather, 1899

Superfamília DENDROCRINACEA Bather, 1899

Família BOTRYOCRINIDAE Wachsmuth and Springer, 1886

Gênero Costalocrinus Jaekel, 1918

Costalocrinus? sp.

(figura 6A-N)

Gênero Cyclocaudex, Scheffler, 2004a, p. 41.

ø Cyclocaudex jucundus, Scheffler, 2004b, p. 146-148, estampa 6, figs. 6-11.

ø Cyclocaudex paranaensis sp. n., Scheffler \& Fernandes, 2007a, p. 90-92, fig. 6.

Costalocrinus? sp., Scheffler, 2010, p. 171-176, estampa 15, figuras 1-3, 5-8, 11-14; estampa 27, figuras 21-22.

Espécie-tipo: Costalocrinus dilatatus, Schultze, 1867.

Material: Espécimens CPg004a e presentes nas amostras CT081 (A-B), CT046 (A-B).

Procedência: km 3 e km 4,4 do Afloramento Jaguariaíva.

Unidade litoestratigráfica: Base da Formação Ponta Grossa, idade Praguiana.

Descrição: Cálice apresentando parte do pedúnculo e dos braços articulados. $\mathrm{O}$ cálice, apesar de completo, está muito mal preservado e não é possível visualizar com certeza a posição das placas. Cálice baixo e globoso, mais largo que alto, aparentemente formado por cinco radiais grandes que se tocam, formando quase todo o copo dorsal (figura 6A, B). Radiais parecem ser pentagonais, bem mais largas que altas, e ocupar mais da metade da altura da teca, sendo bem convexas externamente. Radial apresenta uma lobação que provavelmente representa uma crista mediana pouco evidente. Faceta de articulação entre a radial e a primeira primibraquial larga, porém menor que a largura total da radial. Faceta inclinada para fora (declivada), em forma de ferradura com uma leve crista transversa. Basais bem menores que as radiais e infrabasais desconhecidas. Não ocorrem braquiais fixas. Braços robustos, que se ramificam pelo menos duas vezes isotômicamente? (figura 6A, B). Primeira primibraquial axilar. Três secundibraquiais, a terceira axilar. Na mesma amostra ocorre uma axilar isolada idêntica às outras, porém bem menor, o que indica que os braços são longos, ramificando-se ao menos três vezes isotomicamente? As braquiais são tão ou menos altas quanto largas, apresentando grande sulco adoral. Superfície articular portando uma crista flucral leve, como na radial; aboralmente a essa crista situa-se o canal neural, rodeado por oito pequenos dentículos; superfície da articulação (campos ligamentares) côncava (figuras 61, M). Saco anal de tamanho médio, restrito ao inter-raio CD, fino, composto por diversas placas e afilando lentamentepara o topo. Apresenta uma pequena projeçãolateral próximoaotopo. Tamanho exato, forma e disposição das placas não visíveis. Pedúnculo heteromórfico e circular, noditaxe com dezesseis colunais e quatro ordens de internodais (434243414342434N).

2 A descrição do pedúnculo foi retirada de Scheffler \& Fernandes (2007a), sendo realizadas complementações. 
Colunais do tipo pentâmeras; padrão heteromórfico mais pronunciado na região proximal e tornando-se obscuro para a região distal; na região proximal, as colunais nodais diferem das internodais pela maior altura e pelo diâmetro levemente maior, sendo que em direção distal as internodais adquirem o mesmo diâmetro das nodais, diferindo apenas levemente em altura (figuras 6C, F, G); colunais com látera lisa (sem ornamentação), simétricas, levemente convexas longitudinalmente na região proximal e retas na região distal; suturas do tipo simplectial, com média à larga crenulação; superfície articular com aproximadamente 40 a 50 cúlmens relativamente largos, compridos, retos e simples; lúmen circular, muito largo (figuras $6 \mathrm{~L}, \mathrm{~N}$ ); nodais apresentando cirros no terço distal da pluricolunal (apenas um cirro por nodal visualizado; figuras $6 \mathrm{H}, \mathrm{K}$ ); a cicatriz cirral, que ocupa toda a altura da nodal, possui um pequeno lúmen circular rodeado por cúlmens largos, que se estendem do lúmen até a margem, aumentando em espessura em direção à periferia; cirros duplamente ou triplamente bifurcados, tendo quatro ou oito extremidades livres, com diâmetro diminuindo em direção distal; cirrais mais largas que altas proximalmente, tornando-se gradativamente mais altas que largas entre as duas primeiras bifurcações; suturas entre as cirrais levemente crenuladas. Medidas da amostra CT 081A retiradas da proxistele: NKD - 6,5 mm; NKH - 1,05 mm; NKHi - 16,2 mm; INKD - 5,85 mm; NT - 4,7 mm (noditaxe mascarado aparentemente com oito colunais); $\mathrm{Ni}-22,3$ $\mathrm{mm}$. Medidas da mesma amostra retiradas da dististele: NKD - 8,262 mm; INKD - 8,262 mm; diâmetro da cicatriz cirral - 1,25 mm; comprimento máximo observado do cirro: $40 \mathrm{~mm}$. A amostra CT 081 possui dois fragmentos longos que pertencem ao mesmo indivíduo, estando preservado proxistele, mesistele e dististele; sendo que o comprimento dos dois fragmentos somados é de $21,5 \mathrm{~cm}$, portando aproximadamente 290 colunais.

Discussão: Apesar de a forma e a disposição das placas do cálice não poderem ser visualizadas, diversas características levam a enquadrar os exemplares da Formação Ponta Grossa na família Botryocrinidae (MCINTOSH, 1984), entre elas: cálice baixo, globoso, faceta da radial ocupando mais da metade da largura da radial, braços ramificando-se na parte mais proximal, pedúnculo pentamérico com cirros na região distal. Dos gêneros aceitos para Botryocrinidae por McIntosh (1984), aquele que mais se assemelha ao material do Paraná é o gênero Costalocrinus, típico do Devoniano Inferior ao Carbonífero inferior da Europa e dos Estados Unidos. As semelhanças do material da Formação Ponta Grossa com esse gênero são: a placa radial é a maior placa do cálice; faceta da radial média para ampla, levemente côncava em forma de U, moderadamente declivada; presença de crista transversa fraca na faceta da radial e nas primeiras braquiais, com canal axial aparentemente não completamente separado do sulco adoral, largo e em forma de V; pedúnculo heteromórfico, tipicamente com grande diâmetro (está entre os maiores dos cladidas do Devoniano), com grande lúmen circular, pentamérico, com cirros ramificados na dististele. Para McIntosch (1984) e Kammer (2001), Costalocrinus é muito similar a Brotryocrinus com relação ao cálice, diferindo por uma parte deprimida na área anal e uma Anal X, características não visíveis no material paranaense. No entanto, optou-se por inserir provisoriamente no gênero Costalocrinus devido à morfologia da faceta articular (largo canal axial), ao pedúnculo pentamérico bem evidente e pelos cirros bi- 
furcados. Apesar dessas semelhanças, as características diagnósticas do gênero não estão preservadas, e diferenças na forma do saco anal e na forma das braquiais, na posição de ramificação e no tipo de ramificação diferem levemente do gênero acima e, portanto, a nomenclatura permanece em aberto. Além disso, diversas características aproximam o material da superfamília Cyathocrinitacea: a presença de saco anal não muito longo e de braços unisseriados, ramificando isotomicamente? (ver Moore et al., 1978); a faceta articular da radial com forma de ferradura não ocupando todo o diâmetro da radial e a presença de crista mediana definindo três campos faciais são típicos da articulação do tipo cyathocrinoide (VAN SANT \& LANE, 1964). A presença de primeira primibraquial axilar aproxima esse crinoide da família Cyathocrinitidae. Apesar dessas semelhanças com Cyathocrinitacea, algumas questões podem ser levantadas: a faceta do tipo cyathocrinoide ocorre também em Dendrocrinitacea, tubos anais reduzidos também ocorrem em Botryocrinidae, apesar de mais raros, e as características de pedúnculo (conforme KAMMER \& GHAN, 2003, em Cyathocrinitidae é tipicamente circular, holomérico e essa característica serve para diferenciar Barycrinus de Cyathocrinites) são muito mais similares à família Botryocrinidae (sensu MCINTOSH, 1984). Essas características do pedúnculo são típicas da família que Barycrinus sp., do Carbonífero inferior da Inglaterra, que foi definido apenas com base no pedúnculo por Donovan \& Veltkamp (1990, figs. 1.1, 1.2). A morfologia da faceta dessa espécie é muito similar ao material do Paraná (estampa 15, figura 14), inclusive com a aréola em forma de bacia (jugula); o mesmo pode ser comparado para Costalocrinus sentosus com relação à morfologia da látera e faceta das colunais e também a morfologia da faceta da radial (MCINTOSH, 1984, figs. 2, 3E, 3F). Além disso, a presença da primeira primibraquial axilar em Costalocrinus sp. pode, devido à má preservação, estar mascarada e a primaxilar pode ser a segunda primibraquial, devido à tendência na família de redução em altura, principalmente das primibraquiais, fazendo com que a secundibraquial possa, muitas vezes, estar em contato com a radial. Da mesma forma, saco anal bifurcado já foi descrito para C. sentosus do Givetiano dos Estados Unidos. A taxonomia da ordem Cladida ainda não está muito bem resolvida, tanto que deve representar um grado antes que um clado, sendo possivelmente polifilética (KAMMER \& AUSICH, 1996), e a relação entre diversos grupos afastados na sistemática tradicional (como Cyathocrinitidae e Botryocrinidae) ainda não está bem definida. Existem grandes similaridades entre a linhagem Botryocrinus-Costalocrinus-Barycrinus da subordem Dendrocrinacea e os crinoides Cyathocrinina, tanto que Barycrinus foi posicionado dentro desse táxon pelo Treatise on Invertebrate Paleontology (Moore et al., 1978) e por Donovan \& Velkamp (1990), e na subordem Dendrocrinina por McIntosch (1984) e Ghan \& Kammer (2002), e diversas espécies do gênero Barycrinus já foram classificadas inicialmente ou confundidas com Cyathocrinites (ver KAMMER \& AUSICH, 1996; GHAN \& KAMMER, 2002). Portanto, o material do Paraná é colocado provisoriamente no gênero Costalocrinus e o posicionamento exato permanece em aberto até que novos achados possam elucidar melhor sua morfologia. 
Figura 6. Costalocrinus sp.: A - cálice articulado a fragmentos dos braços e à proxistele do pedúnculo (CPg004a); B - detalhe da figura anterior; C - pluricolunal articulada ao cálice da figura 5A, apresentando noditaxe com oito colunais; D - pluricolunal com padrão similar a mesistele de Costalocrinus? sp. (UNIRIO-077-Eq); E - detalhe da pluricolunal da figura 5C (as setas indicam as suturas dos pentâmeros); F - vista geral de pedúnculo com proxistele, mesistele e dististele (CT081B); G - detalhe da proxistele do pedúnculo da figura anterior (as setas indicam as nodais); $\mathbf{H}$ - detalhe da amostra da figura 5F, mostrando parte da proxistele articulada, o cirro bifurcado, além de braquiais e pentâmeros desarticulados; I detalhe da pluricolunal da figura 5D (as setas indicam a posição de nodais); J - pluricolunal com padrão similar a mesistele de Costalocrinus? sp. (UNIRIO-029-Eq); K - detalhe da dististele do pedúnculo da figura 5F, mostrando as cicatrizes de articulação dos cirros; $\mathbf{L}$ - detalhe da figura $5 \mathrm{H}$, apresentando a morfologia da braquial e de diversos pentâmeros (a seta indica o pentâmero usado para a reconstituição da figura $5 \mathrm{~N}) ; \mathbf{M}$ - faceta da braquial encontrada isolada na mesma amostra do cálice (CPg004a); $\mathbf{N}$ - reconstituição da faceta da colunal a partir do pentâmero desarticulado indicado por seta na figura $5 \mathrm{~L}$

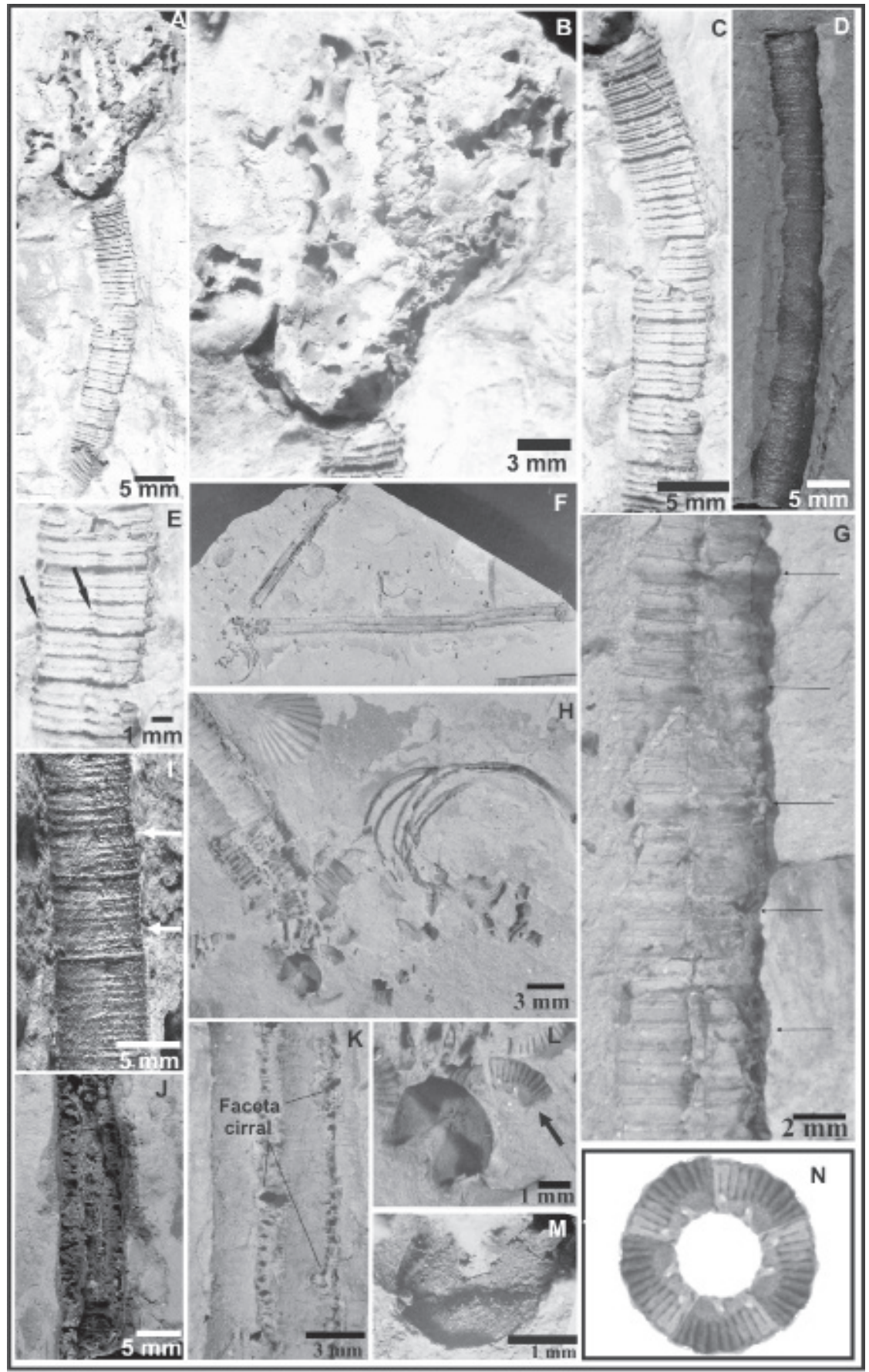




\section{PALEOECOLOGIA E EVOLUÇÃO}

Com relação à morfologia dos braços, é interessante comentar que a grande largura do sulco adoral (canal ambulacral) indica uma especialização em direção a uma dieta em presas maiores que a maioria dos crinoides. Isso é uma característica da família Botryocrinidae que, conforme McIntosh (1984), provavelmente se alimenta de presas grandes capturadas ativamente $(1 \mathrm{~mm}$ a $8 \mathrm{~mm}$, baseado no diâmetro do canal ambulacral através do tegmen), que seriam levadas diretamente à boca pelas râmulas bem desenvolvidas, além de partículas menores, que seriam levadas através dos pódios pelo canal ambulacral, como normalmente ocorre em crinoides atuais. A largura do sulco adoral em uma braquial proximal do material paranaense indica que presas menores desse crinoide poderiam ter até $2 \mathrm{~mm}$ (estampa 15, figura 12). Com relação ao pedúnculo, o tipo de estrutura de ancoragem com cirros ramificados na dististele, disposto radialmente, daria a esses crinoides uma grande estabilidade em substratos moles (MCINTOSH, 1984), o que permitiria permanecerem elevados a alturas consideráveis do substrato. A mesma interpretação para esse tipo de estrutura de ancoragem já havia sido feita por Brett (1981), para quem é muito provável que o grande número de formas paleozoicas - nas quais os cirros estão mais ou menos simetricamente distribuídos e restritos à região distal do pedúnculo - servem para que mantenham uma postura vertical, com o fim do pedúnculo enterrado no substrato mole. Portanto, conforme McIntosh (1984), essa família manteria seu pedúnculo ereto e capturaria suas presas bem acima do substrato. Outra questão reveste de interesse os achados da Formação Ponta Grossa, pois os cirros bifurcados de Botryocrinidae, conforme McIntosh (1984), eram robustos e tipicamente imóveis. Ao observar os cirros dupla ou triplamente bifurcados de Costalocrinus? sp. é possível perceber que estes são bastante delicados e longilíneos, apresentando uma acentuada curvatura, indicando que os mesmos possivelmente poderiam apresentar uma grande flexibilidade na direção aboral-adoral, não sendo tão restritos ao fim do pedúnculo. Esse tipo de cirros é registrado pela primeira vez para o gênero e pode representar uma retenção de caracteres mais basais da linhagem associados aos cirros mais finos do gênero Botryocrinus, gênero em que se encontra o possível ancestral de Costalocrinus. Postura alimentar com captura "ativa" de grandes presas, levadas diretamente à boca por fortes râmulas, pedúnculo com grande diâmetro e comprimento considerável e cirros longelíneos e mais delicados na região distal que nas demais espécies do gênero, poderiam indicar que Costalocrinus? sp. viveria em ambientes com substrato mole, sujeitos a correntes fracas. No entanto, o gênero Costalocrinus possivelmente seria generalista, sendo capaz de capturar zooplancton ativamente em uma ampla gama de ambientes, como já comentado por Kammer (2001), quando discorreu a respeito da grande longevidade do gênero. Os espécimens UNIRIO-29EQ UNIRIO-76EQ, UNIRIO-77EQ, coletados no Afloramento Curva

do Trilho II, parecem possuir o mesmo padrão de pedúnculo, no entanto, os espécimens não estão muito bem preservados, o que impossibilita a atribuição com certeza à Costalocrinus? sp. (figura 6D, I, J). 


\section{OBSERVAÇÕES}

Os pedúnculos das asmostras CT081 e CT046 foram classificados por Scheffler (2004a, b) e por Scheffler \& Fernandes (2007a) no gênero Ciclocaudex, porém o encontro de novo material associado ao cálice permitiu reinterpretar algumas características morfológicas e incluir esse padrão morfológico dentro da sistemática formal da classe. As braquiais isoladas encontradas na amostra CT 081 (A-B) realmente pertencem a essa espécie, como já comentado por Scheffler \& Fernandes (2007a). O mesmo parece que pode ser dito para as braquiais e pluribraquial encontradas na amostra CPg-460.

\section{AFINIDADES PALEOBIOGEOGRÁFICAS E CONSIDERAÇÕES FINAIS}

O número de espécies de crinoides do Devoniano da América do Sul é muito reduzido, quando comparado à fauna do mesmo período da Europa e América do Norte. Na tabela 1, é possível ver a relação dos táxons descritos com base na taxonomia formal do grupo, país, autor e ano da identificação. Até o momento, foram identificados 26 táxons ${ }^{3}$ de crinoides, sendo 16 em nível específico, 08 em nível genérico e 02 em nível de família, além de outros dois táxons identificados com base em uma parataxonomia de pedúnculos. Desses 26 táxons, 13 representam gêneros ou espécies endêmicas da América do Sul, típicos representantes do Domínio Malvinocáfrico (a exceção é Bogotacrinus scheibei, pois a Colômbia faz parte do Subdomínio Appohimchi, do Domínio das Américas Orientais, sensu BOUCOT, 1975). É importante lembrar que Ophiocrinus stangeri, apesar de não ser endêmico da América do Sul, é endêmico do Domínio Malvinocáfrico. De todos os gêneros citados, apenas Ctenocrinus e Cyathocrinites são táxons cosmopolitas com distribuição geográfica ao redor do mundo, reforçando o caráter mais restrito da fauna sul-americana.

${ }^{3}$ Haude (2004) cita que existem 15 espécies de crinoides na Argentina (Formação Talacasto): 5 cameratas, 7 cladidas, 2 disparidas, 1 flexivel. No entanto, a maior parte destas espécies não foram publicadas. 
Tabela 1. Táxons de crinoides identificados com base na taxonomia formal do grupo para o Devoniano da América do Sul * Táxons endêmicos da América do Sul

\begin{tabular}{|c|c|c|c|c|}
\hline PAIS & $\begin{array}{l}\text { IDADE/UNIDADE } \\
\text { GEOLÓGICA }\end{array}$ & $\begin{array}{l}\text { IDENTIFICAÇÕES } \\
\text { ANTERIORES }\end{array}$ & $\begin{array}{c}\text { TÁXONS ATUALMENTE } \\
\text { VÁLIDOS }\end{array}$ & SUB-CLASSE \\
\hline Brasil* & $\begin{array}{c}\text { Eifeliano } \\
\text { (Formação } \\
\text { Pimenteira) }\end{array}$ & & $\begin{array}{l}\text { Monstrocrinus incognitus (Scheffler } \\
\text { et al., 2011) }\end{array}$ & $\begin{array}{c}\text { Camerata } \\
\text { Diplobathrida }\end{array}$ \\
\hline Brasil & $\begin{array}{l}\text { Eifeliano (Formação } \\
\text { Maecuru) } \\
\end{array}$ & & $\begin{array}{c}\text { Monstrocrinus securifer (Schffler et } \\
\text { al., 2006) }\end{array}$ & $\begin{array}{c}\text { Camerata } \\
\text { Diplobathrida } \\
\end{array}$ \\
\hline Brasil & $\begin{array}{l}\text { Eifeliano (Formação } \\
\text { Maecuru) }\end{array}$ & $\begin{array}{c}\text { Ctenocrinus sp. } \\
\text { (Katzer, 1903, 1933) }\end{array}$ & $\begin{array}{c}ø \text { Laudonomphalus regularis (Schffler } \\
\text { et al., 2006) }\end{array}$ & Camerata? \\
\hline Brasil* & $\begin{array}{l}\text { Givetiano (Formação } \\
\text { Ererê) }\end{array}$ & $\begin{array}{c}\text { Ctenocrinus sp. } \\
\text { (Katzer, 1903, 1933) }\end{array}$ & $\begin{array}{c}ø \text { Botryocrinus melloi (Scheffler et } \\
\text { al., 2013, no prelo) }\end{array}$ & Cladida \\
\hline Brasil & $\begin{array}{l}\text { Praguiano (Formação } \\
\text { Ponta Grossa) }\end{array}$ & $\begin{array}{c}\text { Ophiucrinus stangeri } \\
\text { (Scheffler \& } \\
\text { Fernandes, 2007a) }\end{array}$ & Ophiocrinus stangeri (neste artigo) & $\begin{array}{c}\text { Camerata } \\
\text { Diplobathrida }\end{array}$ \\
\hline Brasil & $\begin{array}{l}\text { Devoniano Inferior? } \\
\text { (Formação Ponta } \\
\text { Grossa?) }\end{array}$ & & Monobathrida indet. (neste artigo) & $\begin{array}{c}\text { Camerata } \\
\text { Monobathrida }\end{array}$ \\
\hline Brasil & $\begin{array}{c}\text { Praguiano/Emsiano? } \\
\text { (Formação Ponta } \\
\text { Grossa) }\end{array}$ & $\begin{array}{c}\text { Poteriocrinida } \\
\text { indet. (Scheffler \& } \\
\text { Fernandes, 2007a) } \\
\end{array}$ & Ctenocrinus sp. (neste artigo) & $\begin{array}{c}\text { Camerata } \\
\text { Monobathrida }\end{array}$ \\
\hline Brasil & $\begin{array}{l}\text { Praguiano (Formação } \\
\text { Ponta Grossa) }\end{array}$ & $\begin{array}{l}ø \text { Cyclocaudex } \\
\text { paranaensis (Scheffler } \\
\text { \& Fernandes, 2007a) } \\
\end{array}$ & Costalocrinus? sp. (neste artigo) & Cladida \\
\hline Bolívia & Devoniano Inferior & $\begin{array}{l}\text { Ctenocrinus sp. } \\
\text { (Ulrich, 1892; Knod, } \\
\text { 1908) }\end{array}$ & $\begin{array}{c}\varnothing \text { Laudonomphalus regularis (neste } \\
\text { artigo) }\end{array}$ & Camerata? \\
\hline Bolívia & $\begin{array}{c}\text { Emsiano (Formação } \\
\text { Belén) } \\
\end{array}$ & & $\begin{array}{c}\varnothing \text { Costalocrinus? sp. (McIntosh, } \\
\text { 1984) }\end{array}$ & Cladida \\
\hline Bolívia* & $\begin{array}{l}\text { Eifeliano (Formação } \\
\text { Sicasica) e Emsiano } \\
\text { (Formação Belen) }\end{array}$ & & $\begin{array}{c}\text { Boliviacrinus isaacsoni } \\
\text { (McIntosh,1988; Thompson et al., } \\
\text { 2013) }\end{array}$ & $\begin{array}{c}\text { Camerata } \\
\text { Monobathrida }\end{array}$ \\
\hline Bolívia* & $\begin{array}{c}\text { Emsiano (Formação } \\
\text { Belén) }\end{array}$ & & $\begin{array}{l}\text { Apurocrinus sucrei (McIntosh,1981; } \\
\text { Thompson et al., 2013) }\end{array}$ & $\begin{array}{c}\text { Camerata } \\
\text { Diplobathrida }\end{array}$ \\
\hline Bolívia* & $\begin{array}{l}\text { Emsiano (Formação } \\
\text { Icla) }\end{array}$ & & $\begin{array}{l}\text { Lutocrinus boliviaensis (Thompson } \\
\text { et al., 2013) }\end{array}$ & $\begin{array}{c}\text { Camerata } \\
\text { Diplobathrida }\end{array}$ \\
\hline Bolívia* & $\begin{array}{l}\text { Emsiano (Formação } \\
\text { Icla) }\end{array}$ & & $\begin{array}{l}\text { Griphocrinus pirovanoi } \\
\text { (Thompson et al., 2013) }\end{array}$ & $\begin{array}{c}\text { Camerata } \\
\text { Diplobathrida }\end{array}$ \\
\hline Bolívia* & $\begin{array}{l}\text { Emsiano (Formação } \\
\text { Icla) }\end{array}$ & & $\begin{array}{c}\text { Ctenocrinus branisai } \\
\text { (Thompson et al., 2013) }\end{array}$ & $\begin{array}{c}\text { Camerata } \\
\text { Monobathrida }\end{array}$ \\
\hline Bolívia & $\begin{array}{c}\text { Emsiano (Formação } \\
\text { Belen) } \\
\end{array}$ & & $\begin{array}{l}\text { ?Botryocrinus sp. } \\
\text { (Branisa, 1965) }\end{array}$ & Cladida \\
\hline $\begin{array}{l}\text { Ilhas } \\
\text { Malvinas* }\end{array}$ & $\begin{array}{l}\text { Devoniano Inferior } \\
\text { (Formação Fox Bay) }\end{array}$ & $\begin{array}{c}\text { Botryocrinus doublet } \\
\text { Kirk (1913; In: Clarke, } \\
\text { 1913) }\end{array}$ & $\begin{array}{c}\text { Pyrenocrinus? doubleti (McIntosh, } \\
\text { 1983) }\end{array}$ & Cladida \\
\hline Antártica & $\begin{array}{c}\text { Praguiano/Emsiano, } \\
\text { (Formação Horlick) }\end{array}$ & & $\begin{array}{l}\text { Ancyrocrinus? sp. (McCartan, } 1981 \\
\text { apud Boucot \& Rachebouef, 1993) }\end{array}$ & Cladida \\
\hline Colômbia* & $\begin{array}{l}\text { Emsiano/Eifeliano } \\
\text { (Formação Floresta) }\end{array}$ & & $\begin{array}{c}\text { Bogotacrinus scheibei } \\
\text { (Schmidt, } 1937 \text { apud McIntosh, } \\
\text { 1987) }\end{array}$ & $\begin{array}{c}\text { Camerata } \\
\text { Diplobathrida }\end{array}$ \\
\hline
\end{tabular}


Sandro Marcelo Scheffler; Antonio Carlos Sequeira Fernandes; Vera Maria M. Fonseca

conclusão.

\begin{tabular}{|c|c|c|c|c|}
\hline Argentina & $\begin{array}{l}\text { Praguiano/Emsiano } \\
\text { (Fm. Talacasto) }\end{array}$ & & $\begin{array}{l}\text { Bridgerocrinus sp. } \\
\text { (Waisfeld, 1989) }\end{array}$ & Cladida \\
\hline PAIS & $\begin{array}{l}\text { IDADE/UNIDADE } \\
\text { GEOLÓGICA }\end{array}$ & $\begin{array}{l}\text { IDENTIFICAÇÕES } \\
\text { ANTERIORES }\end{array}$ & $\begin{array}{c}\text { TÁXONS ATUALMENTE } \\
\text { VÁLIDOS }\end{array}$ & SUB-CLASSE \\
\hline Argentina & $\begin{array}{l}\text { Praguiano/Emsiano } \\
\text { (Fm. Talacasto) }\end{array}$ & $\begin{array}{l}\text { Cyathocrinus elongatus } \\
\text { (Knod, 1908) }\end{array}$ & $\begin{array}{c}\text { Cyathocrinites elongatus (Castellaro, } \\
1966 \text { apud Waisfeld, 1989) }\end{array}$ & Cladida \\
\hline Argentina & $\begin{array}{l}\text { Praguiano/Emsiano } \\
\text { (Fm. Talacasto) }\end{array}$ & & $\begin{array}{l}\text { Calceocrinidae } \\
\text { (Waisfeld, 1989) }\end{array}$ & Disparida \\
\hline Argentina* & $\begin{array}{l}\text { Praguiano/Emsiano } \\
\text { (Fm. Talacasto) }\end{array}$ & & $\begin{array}{c}\text { Pterinocrinus? australis (Haude, } \\
\text { 1995) }\end{array}$ & $\begin{array}{c}\text { Camerata } \\
\text { Diplobathrida }\end{array}$ \\
\hline Argentina* & $\begin{array}{l}\text { Praguiano/Emsiano } \\
\text { (Fm. Talacasto) }\end{array}$ & & $\begin{array}{c}\text { Radicalcarocrinus huenickeni } \\
\text { (Haude, 1995) }\end{array}$ & Disparida \\
\hline Argentina & $\begin{array}{l}\text { Praguiano/Emsiano } \\
\text { (Fm. Talacasto) }\end{array}$ & & $\begin{array}{l}\text { Maragnicrinus? sp. (Webster, 1997, } \\
\text { apud Webster, 2000) }\end{array}$ & $\begin{array}{c}\text { Cladida } \\
\text { poteriocrinoide }\end{array}$ \\
\hline Argentina* & $\begin{array}{l}\text { Praguiano/Emsiano } \\
\text { (Formação Talacasto) }\end{array}$ & & $\begin{array}{l}\text { Acanthocrinus? benedettoi. (Haude } \\
\text { 2004) }\end{array}$ & $\begin{array}{c}\text { Camerata } \\
\text { Diplobathrida }\end{array}$ \\
\hline Argentina* & $\begin{array}{c}\text { Praguiano/Emsiano } \\
\text { (Formação Talacasto) }\end{array}$ & & Manocrinus maldigitus (Haude 2004) & Cladida \\
\hline
\end{tabular}

Quando observada a lista de crinoides gondwanicos do Devoniano Inferior apresentada por Webster (2000), complementada com as identificações de Haude (2004), Scheffler (2007a), Thompsom et al. (2013), e as deste artigo, é possível notar que, quando se exclui o norte da África e o restante do Gondwana setentrional (Armorica, Península Ibérica, Bohemia), poucos gêneros de crinoides ocorrem em mais de um país que compunha o antigo continente Gondwana: Ophiocrinus no Brasil, Austrália e na África do Sul; Ctenocrinus no Brasil, na Bolívia e na Austrália; e Costalocrinus no Brasil e na Bolívia. Esse fato provavelmente está relacionado com o pequeno número de trabalhos com crinoides do Gondwana, principalmente na América do Sul e África do Sul.

Devido as grandes similaridades da fauna malvinocáfrica, principalmente no Devoniano Inferior, entre Bolívia, Brasil (principalmente na Bacia do Paraná), Argentina, Uruguai, Ilhas Malvinas, Antártica e África do Sul, seria de se esperar que esses países apresentassem mais táxons em comuns, como evidenciado também pela presença do gênero de blastoide Pachyblastus no Emsiano do Brasil (SCHEFFLER \& FERNANDES, 2007b), Bolívia (MACURDA, 1979) e África do Sul (JELL \& THERON, 1999). Essa estranha ausência de similaridade entre África do Sul e América do Sul já havia sido notada por Jell \& Theron (1999), que comentaram que os equinodermas da África do Sul, no atual estágio de conhecimento, parecem ter mais táxons afins com a América do Norte e a Europa, mas que, no entanto, estudos futuros com os equinodermas da América do Sul podem revelar uma maior afinidade, como ocorre com outros invertebrados da fauna malvinocáfrica, tais como os braquiópodes.

A fauna de crinoides da América do Sul é dominada por Cameratas, principalmente da ordem Diplobathrida. Esse é um fato estranho quando analisamos as chamadas Faunas Evolucionárias de Crinoides (CEF - Crinoid Evolutionary Fauna) estabelecidas para o Paleozoico por Baumiller (1994) e Ausich et al. (1994). Conforme Ausich (2009) durante o Paleozoico existiram três CEF tipicamente caracterizadas pela predominância 
de ordens distintas de crinoides: (i) a CEF do Paleozoico inicial ocorreu no Ordoviciano e predominaram cameratas diplobatridas, disparidas e hibocrinoides; (ii) a CEF do Paleozoico Médio ocorreu do Siluriano até o início do Carbonífero e predominaram cameratas monobatridas, cladidas e crinoides flexíveis; (iii) e a CEF do Paleozoico tardio ocorreu do Carbonífero médio até o final do Permiano, com predominância absoluta de cladidas avançados. Portanto, a grande abundância de diplobatridas em depósitos sedimentares do Devoniano da América do Sul é um fato inusitado.

Novamente, é digna de nota a diferença dos táxons entre localidades diferentes da fauna malvinocáfrica. Enquanto na América do Sul os diplobatridas são muito abundantes e diversos, na África do Sul a proporção esperada entre as ordens é encontrada com o predomínio absoluto de cladidas, seguido pelos monobatridas (figura 7). Chama atenção no gráfico que em termos absolutos os números de cladidas e monobatridas são muito semelhantes entre os dois continentes, ficando a discrepância por conta da exagerada proporção de diplobatridas na América do Sul. A ocorrência em menor proporção dos cladidas também pode se dever à falta de estudos na América do Sul, como pode ser exemplificado pelo caso de Branisa (1965), que citou vários cálices de crinoides indeterminados, dos quais pelo menos dois são cladidas. No entanto, é possível que esses mares epicontinentais de águas frias representassem um refúgio para a ordem Diplobathrida, que estava em declínio nos mares tropicais a temperados do Domínio do Velho Mundo e do Domínio das Américas Orientais.

Figura 7. Número de táxons identificados na América do Sul e na África do Sul. Estão incluídos apenas os táxons identificados através da sistemática formal da classe

\section{Número de crinoides por Ordens}

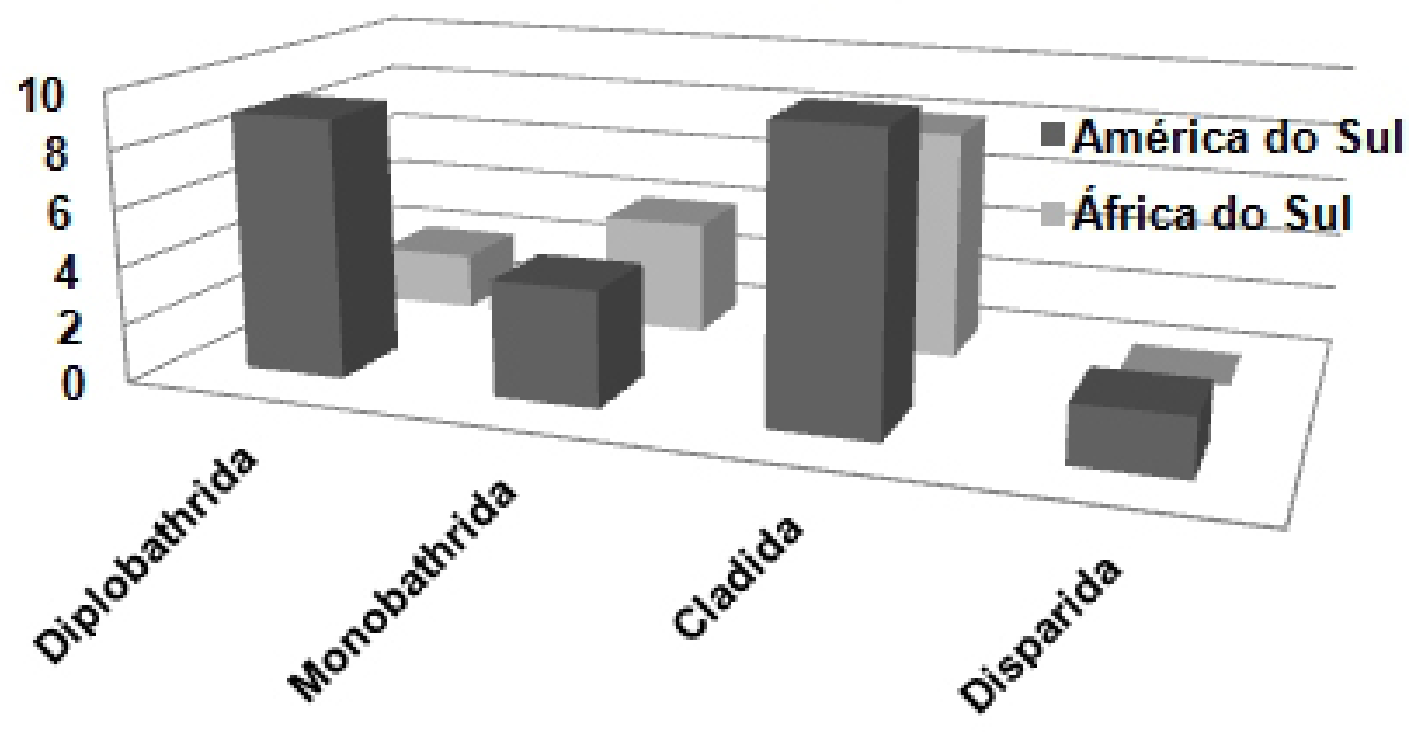


A fauna da América do Sul como um todo, incluindo a Malvinocáfrica, apesar do forte endemismo, apresenta uma marcada influência de formas do Maciço Xistoso Renano (sul da Báltica), Maciço Armoricano, Península Ibérica, Bohemia e norte da África (norte do Gondwana; Domínio Ibarmaghiano, sensu PLUSQUELLEC et al., 1997), o que parece indicar, como comentado por outros autores, que o oceano Reico sofreu uma redução significativa, principalmente a partir do Emsiano, e não representava uma barreira efetiva para dispersão de muitas espécies (e.g. MORZADEC et al., 1988; PLUSQUELLEC et al., 1997). Nossos dados também parecem confirmar que o Maciço Armoricano e a península Ibérica deveriam estar posicionados muito próximos ao norte da África, com a inexistência de um oceano Protothetis, como já argumentado por diversos autores (e.g. MORZADEC et al., 1988; SCOTESE \& Mckerrow, 1990; LE MENN, 1997a; PLUSQUELLEC et al., 1997; ROBARDET, 2003). Influência de formas do norte do Gondwana (sub-domínio Ibarmaghiano) e do sul da Báltica (Maciço Xistoso Renano) na América do Sul já foi anteriormente citada para outros grupos (e.g. cefalópodes - THROT et al., 2011; braquiópodes - ISAACSON \& PERRY, 1977; FONSECA \& MELO, 1987; hiolitideos - MAREK \& ISASCSON, 1992 apud ISAACSON, 1996).

Nos crinoides, entre os vários exemplos dessa influência, podemos citar a família Pterinocrinidae, que é representada na América do Sul pelos dois gêneros endêmicos Apurocrinus e Boliviacrinus (MCINTOSH, 1981, 1987) e a espécie endêmica Pterinocrinus? australis (HAUDE, 1995). Essa família surge no Maciço Xistoso Renano no Praguiano/ Emsiano e rapidamente se espalha para a Armórica, península Ibérica, norte da África (MCINSTOSH, 1987; LE MENN \& REGNAULT, 1993) e América do Sul durante o Emsiano, provavelmente via a margem noroeste do Gondwana, e posteriormente chegando no Devoniano Médio na Laurência.

Costalocrinus? sp., assim como Costalocrinus helenae descrito por Schmidt (1941) para o oeste da Alemanha, são os representantes mais antigos conhecidos do gênero, ambos do Praguiano. As únicas espécies conhecidas do Emsiano ocorrem no oeste da Alemanha e Espanha (C. consolidatus SCHMIDT, 1941) e na Espanha (C. ibericus KAMMER, 2001 e C. thymos KAMMER, 2001). McIntosh (1984), baseado em pluricolunais isoladas da coleção Branisa, indicou que possivelmente o gênero pode ocorrer no Emsiano da Bolívia (Formação Belén). No entanto, todos os espécimes que ocorrem nos Estados Unidos são do Devoniano Médio ou do Carbonífero Inferior, o que novamente sugere que o gênero surgiu inicialmente no Maciço Xistoso Renano, em que ocorre até o Eifeliano, e migra rapidamente para o sul durante o Praguiano no norte e sudoeste do Gondwana, adentrando, posteriormente a Laurência somente no Devoniano Médio (Givetiano).

O mesmo parece ocorrer com o gênero Acanthocrinus, que ocorre no Devoniano Inferior da Armórica (França) e da região Renana (Bélgica, Luxemburgo, Alemanha) e do norte do Gondwana (Argélia), e Devoniano Médio (Estados Unidos) no Domínio das Américas Orientais (LE MENN, 1985; LE MENN, 1997B; SUDKAMP, 2013), sendo registrado para o Devoniano Inferior da Argentina (HAUDE, 2004).

Padrão similar pode ser observado para o gênero Griphocrinus, que, conforme Thompsom et al., (2013), ocorre no Devoniano Médio (Givetiano) dos Estados Unidos e da 
Espanha (Couviniano), Devoniano Inferior/Médio da Argélia (Emsiano tardio-Eifeliano) e descrito recentemente para o Devoniano Inferior da Bolívia (Emsiano). Esse gênero pode ter se originado no norte da África ou na América do Sul, porém em ambos os casos envolveu uma rápida migração após seu surgimento demonstrando novamente a afinidade da fauna da América do Sul e do norte da África durante o Emsiano/Eifeliano.

Trajeto parecido, apesar de mais recente, parece ocorrer com o gênero Monstrocrinus, adentrando as bacias do Amazonas e do Parnaíba a partir do norte da África e se estabelecendo durante o Eifeliano médio (SCHEFFLER et al., 2011); Monstrocrinus securifer, um táxon típico do Devoniano inferior (Emsiano) do maciço renano, ocorre no Eifeliano médio a tardio na Bacia do Amazonas (SCHEFFLER et al., 2006). Da mesma forma, Botryocrinus melloi, espécie que ocorre no Givetiano da Bacia do Amazonas (SCHEFFLER et al., 2013, no prelo), apesar de endêmica, é muito semelhante à espécie da Armórica, $B$. montguyonensis, que ocorre no Devoniano inferior.

Um grande número de táxons parece surgir também no Domínio Malvinocáfrico e se espalhar ao redor do mundo, principalmente a partir do Devoniano Médio. É interessante notar que a maioria desses táxons surge no Devoniano Inferior nesse domínio altamente endêmico e migra, principalmente, para o Domínio das Américas Orientais durante o Devoniano Médio.

Entre estes, podemos citar o gênero Ophiocrinus. Apesar do endemismo de O. stangeri, o gênero parece surgir na América do Sul (Praguiano) e posteriormente se espalhado, ainda durante o Devoniano Inferior, para a África do Sul e também para a Austrália, onde ocorre O. mariae. Nos Estados Unidos, essa última espécie vai ocorrer somente no Devoniano Médio.

Conforme McIntosh (1983), o mesmo parece ocorrer para o gênero Pyrenocrinus, abundante no Givetiano da América do Norte. Se confirmada a atribuição de P.? doubleti a esse gênero, representaria que o mesmo surgiu como um típico táxon malvinocáfrico e posteriormente migrou para a Laurência.

Cabe, neste momento, citar também o blastoide Brachyschisma? gamonedensis (RACHEBOEUF et al., 1998), descrito para o Praguiano da Bolívia. O gênero parece surgir na Bolívia, migrando para a África do Sul ainda no Devoniano Inferior (Emsiano, $B$. oostheizeni; JELL \& THERON, 1999) e posteriormente no Devoniano Médio para os Estados Unidos (Eifeliano e Givetiano de Nova Iorque, Brachyschisma corrugatum; RACHEBOEUF et al., 1998).

Outros exemplos são: Maragnicrinus - Devoniano Inferior da Argentina e Devoniano Médio de Nova Iorque (EUA); Bridgerocrinus - Devoniano Inferior da Argentina, Devoniano Superior (Fameniano) do Irã, China e Inglaterra e Carbonífero Inferior dos Estados Unidos. Ambos os gêneros são possivelmente malvinocáfricos que se espalharam no Devoniano Médio para a Laurússia.

No entanto, não podemos deixar de comentar que existem alguns exemplos, embora poucos, de táxons que parecem ter surgido no Domínio das Américas Orientais e que posteriormente adentraram o oeste/sudoeste do Gondwana. O mais característico é Boliviacrinus isaacsoni, do Eifeliano da Bolívia, que parece representar o membro final dos 
patelliocrinoides e provavelmente se desenvolveu de um estoque ancestral do Siluriano da América do Norte, onde estavam bem estabelecidos (THOMPSON et al., 2013).

Alguns táxons deixam dúvidas em relação aos seus padrões de migração, apesar de demonstrarem que a fauna de equinodermas do Domínio Malvinocáfrico sofria alguma influência do Domínio das Américas Orientais, tais como: Ancyrocrinus, que ocorre no Devoniano Inferior e Médio dos Estados Unidos, Devoniano Médio da Armórica e Devoniano Inferior da Antártica (Ancyrocrinus? sp.); e o blastoide Eleutherocrinus cassedayi conhecido do Givetiano da Bolívia e dos Estados Unidos (MACURDA, 1979).

Esses dados parecem corroborar a hipótese de que uma corrente quente subtropical estava presente durante o Devoniano Inferior e o início do Devoniano Médio, favorecendo a dispersão das faunas Renanas, do sul da Báltica (oeste da Europa), da Armórica e península Ibérica (leste da Europa), e Marrocos e Argélia (Norte da África), do Norte do Gondwana, para a o noroeste, oeste e sudoeste do Gondwana (América do Sul) (ISAACSON \& PERRY, 1977; ISAACSON, 1981; FONSECA \& MELO, 1987; MCINTOSH, 1987; MELO, 1988). Essa entrada de águas quentes estaria relacionada à transgressão marinha (BARRETT \& ISAACSON, 1988; ISAACSON \& SABLOCK, 1990; ISAACSON \& MARTINEZ, 1994; ISAACSON, 1996), que culminaria na passagem Eifeliano/Givetiano com a extinção do Domínio Malvinocáfrico (BOSETTI et al., 2012).

Os dados de equinodermas também parecem corroborar que alguma corrente, principalmente durante o Devoniano Médio, deveria ter existido entre o oeste/sudoeste do Gondwana e a Laurência (América do Norte), que favorecia a dispersão larval dos equinodermas do primeiro para o segundo paleocontinente. Esse padrão de corrente já foi figurado em mapa paleogeográfico apresentado por Isaacson (1996). É bom lembrar que o padrão similar de rota de migração é de longa data conhecido para outros grupos de invertebrados, como o braquiópode Tropidoleptus carinatus (FONSECA \& MELO, 1987). Esse padrão de migração pode ter sido favorecido novamente pela transgressão marinha, porém agora associada a um possível giro anti-horário, citado por Isaacson (1996), que o oeste do Gondwana sofreu entre o Devoniano Médio e o Superior, em direção norte, levando para latitudes mais baixas parte das bacias paleozoicas da América do Sul. No entanto, é importante lembrar que Isaacson (1996), discutindo a distribuição paleobiogeográfica dos braquiópodes da Bolívia, Venezuela e Estados Unidos ("Hamilton fauna"), argumenta que a ausência das formas da Venezuela e dos Estados Unidos, na Bolívia, também pode estar relacionado à configuração das passagens entre bacias, formadas por mares muito rasos, que impediriam aos habitantes de águas mais profundas se dispersarem para a América do Sul.

Esses diversos táxons adentrando o Domínio das Américas Orientais mostram que as faunas malvinocáfricas também contribuíram com elementos para a mudança faunal durante o Eifeliano tardio/Givetiano, já registrada na América do Norte pela invasão de táxons do Domínio do Velho Mundo (e.g. BAILEY, 1978; DESANTIS \& BRETT, 2011). Essas acelerações nas taxas de migração parecem estar associadas, como já comentado, à subida global do nível do mar, aliada às mudanças drásticas de temperatura, que fazem do Devoniano Médio um período crítico para a história da vida (BRETT et al., 2011). 
Apesar dessas evidências, é preciso não esquecer que a fauna de crinoides do Devoniano Inferior apresenta um registro estratigráfico muito rico na Europa e pouco conhecido nos Estados Unidos e, portanto, isso pode estar mascarando os padrões de primeiro aparecimento dos táxons e, consequentemente, suas rotas migratórias. A continuidade dos estudos com a classe na América do Sul pode ajudar a esclarecer melhor essas relações paleobiogeográficas.

\section{AGRADECIMENTOS}

Os autores agradecem a todas as instituições de Ensino e Pesquisa que disponibilizaram suas coleções paleontológicas; à Unidade de Diagnóstico por Imagem e Terapia por Radiações do Hospital de Clínicas da Universidade Federal do Paraná, pelos exames de radiologia e tomografia; ao Biólogo Eduardo Shiichi Suzuki, do Laboratório de Foraminíferos e Micropaleontologia Ambiental (LaFMA), Universidade Federal do Paraná, pela realização de fotografias em série e montagem de imagem com o Microscópio Estereoscópico Zeiss V20 (motorizada); e ao CNPq pelo apoio financeiro para realização do Doutorado do primeiro autor.

\section{REFERÊNCIAS}

AUSICH, W. Crinoids. In: Catalani, John \& Cozart, Chris (eds.). M.A.P.S. Digest, EXPO XXXI Edition. Macomb, Illinois: Western Illinois University, Western Hall, pp. 6-22, 2009.

AUSICH, W. I., KAMMER, T. W., BAUMILLER, T. K. Demise of the Middle Paleozoic crinoid fauna: a single extinction or rapid faunal turnover? Paleobiology, v. 20, pp. 345-361, 1994.

AUSICH, W. I., BARTELS, C., KAMMER, T. W. Tube foot preservation in the Devonian crinoid Codiacrinus from the Lower Devonian Hunsr€uck Slate, Germany. Lethaia, v. 46, pp. 416-420, 2013.

BAILEY, J. B. Procincialism and Migration in Lower and Middle Devonian Pelecypods. Palaeogeography, Palaeoclimatology, Palaeoecology, v. 23, pp. 119-130, 1978.

BARRETT, S. F., ISAACSON, P. E. Devonian paleogeography of South America. In: McMILLAN, N. J.; EMBRY, A. F., GLASS, D. J. (eds.), Devonian of the world. Canadian Society of Petroleum Geologists Memoir, v. 14, n. 1, pp. 655-667, 1988.

BAUMILLER, T. K. Patterns of dominance and extinction in the record of Paleozoic crinoids. In: DAVID, B., GUILLE, A., FERAL, J.P., ROUX, M. Echinoderms Through Time (Echinoderms Dijon). Rotterdam: Balkema, pp. 193-198, 1994.

BOSETTI, E. P., GRAHN, Y., HORODYSKI, R. S., MAULLER, P. M. The first recorded decline of the Malvinokaffric Devonian fauna in the Paraná Basin (southern Brazil) and its cause: taphonomic and fossil evidences. Journal of South American Earth Sciences, v. 37, pp. 1-14, 2012.

BOUCOT, A. J. Malvinokaffric Devonian Marine Community Distribution-and Implications for Godwana. In: SIMPÓSIO BRASILEIRO DE PALEONTOLOGIA, 1, 1970, Rio de Janeiro. Anais da Academia Brasileira de Ciências, Rio de Janeiro: Suppl. 43, pp. 23-49, 1971.

BOUCOT, A.J. Evolution and Extinction Rate Controls. Amsterdan: Elsevier, 427 p., 1975.

BOUCOT, A.J., RACHEBOEUF, P.R. Biogeographic summary of the Malvinokaffric Realm Silurian and Devonian fossils. In:SUAREZ-SORUCO, R. (ed.). Invertebrados y Paleobotanica: Fosiles y Facies de Bolivia. Revista Técnica de YPFB, v. II, p.13-14(1-4): 71-75, 1993. 
BRANISA, L. Los fosiles guias de Bolivia: Paleozoic. Boletin Servicio Geologico de Bolivia, v. 6, pp.1-282, 1965. BRETT, C. E. Terminology and functional morphology of attachment structures in pelmatozoan echinoderms. Lethaia, v. 14, pp. 343-370, 1981.

BRETT, C. E., SCHINDLER, E., KÖNIGSHOF, P. Sea-level cyclicity, climate change, and bioevents in Middle Devonian marine and terrestrial environments: an overview. Palaeogeography, Palaeoclimatology, Palaeoecology, v. 304, pp.1-2, 2011.

BROWER, J. C. Ontogeny of camerate crinoids. The University of Kansas Paleontological Contributions, v. 72, pp. 1-53, 1974.

CASTER, K. E. A new Carpoid Echinoderm from the Paraná Devonian. Anais da Academia Brasileira de Ciências, v. 26, n. 1, pp. 123-147, 1954a.

CASTER, K. E. A. Devonian Placocystoid Echinoderm from Paraná, Brazil. In: LANGE, F. W. (ed.). Paleontologia do Paraná. Curitiba: Comissão de Comemorações do Centenário do Paraná, pp. 137-148, 1954b.

CLARKE, J. M. Fósseis Devonianos do Paraná. Serviço Geológico e Mineralógico do Brasil. Monografia 1, 353 p., 1913.

DERBY, O. A. A Geologia da Região Diamantífera da Província do Paraná. Arquivos do Museu Nacional, v. 3, pp. 89-96, 1878.

DeSANTIS, M.K., BRETT, C. E. Late Eifelian (Middle Devonian) biocrises: Timing and signature of the preKačák Bakoven and Stony Hollow Events in eastern North America. Palaeogeography, Palaeoclimatology, Palaeoecology, v. 304, pp.113-135, 2011.

DONOVAN, S.K., VELTKAMP, C.J. Barycrinus (Crinoidea) from the Lower Carboniferous of England. Journal of Paleontology, v. 64, n. 6, pp. 988-992, 1990.

FEARNHEAD, F. E. Towards a systematic standard approach to describing fossil crinoids, illustrated by the redescription of a Scottish Silurian Pisocrinus de Koninck. Scripta Geologica, v. 136, pp. 39-61, 2008.

FERREIRA, C. S., FERNANDES, A. C. S. Nota sobre alguns crinoides do Devoniano da Amazônia. Anais da Academia Brasileira de Ciências, v. 57, n. 1, p. 139, 1985.

FONSECA, V. M., MELO, J. H. Ocorrência de Tropileptus carinatus (Conrad) (Braquiopoda Orthida) na Formação Pimenteira, e sua importância paleobiogeográfica. In: CONGRESSO BRASILEIRO DE PALEONTOLOGIA, 10, 1987, Rio de Janeiro. Anais... Rio de Janeiro, Sociedade Brasileira de Paleontologia, pp. 505-537, 1987.

GAHN, F. J., KAMMER, T. W. The cladid crinoids Barycinus from the Burlington Limestone (early Osagen) and the phylogenetics of mississipian botryocrinids. Journal of Paleontology, v. 76, n. 1, pp. 123-133, 2002.

GRAHN, Y. Recent Progress in the Silurian and Devonian Chitinozoan Biostratigraphy of the Paraná Basin in Brazil and Paraguay. In: RODRIGUES, M.A.C.; PEREIRA, E. (eds.). Ordovician-Devonian Palynostratigraphy in Western Gondwana: Update, Problems and Perspectives. Rio de Janeiro: Universidade do Estado do Rio de Janeiro, Faculdade de Geologia, pp. 147-164, 1999.

GRAHN, Y., MAULLER, P.M. ; BERGAMASCHI, S. ; BOSETTI, E.P., 2012. Palynology and sequence stratigraphy of three Devonian rock units in the Apucarana Subbasin (Paraná Basin, south Brazil): additional data and correlation. Review of Palaeobotany and Palynology. doi:10.1016/j.revpalbo.2011.10.006 (in press).

HARTT, C.F., RATHBUN, R. Morgan Expedition 1870-1871: on the Devonian trilobites and mollusks of Ererê, province of Pará, Brail. Annals of the Lyceum of Natural History, v. 11, pp. 110-127, 1875.

HAUDE, R. Echinodermen aus dem Unter-Devon der arentinischen Präkordillere. N. Jb. Geol. Paläont. Abh., v. 197, n. 1, pp. 37-86, 1995.

HAUDE, R. Morphology and paleobiology of echinoderms in the Lower Devonian of the Argentine Precordillera. In: HEINZELLER \& NEBELSICK (eds.) Echinoderms. London: Francis \& Taylor group, pp. 417-420, 2004.

ISAACSON, P. E. A Reassessment of Andean Mid-Paleozoic biogeography. In: CONGRESSO LATINOAMERICANO DE PALEONTOLOGIA, 2, 1981, Porto Alegre. Anais... Porto Alegre, Sociedade Brasileira de Paleontologia, pp. 75-78, 1981. 
ISAACSON, P. E. Devonian biogeography and paleogeography of western Gondwana: malvinokaffric endemism, faunal migration, and organic microfossil provincialism. In: SIMPÓSIO SUL AMERICANO DO SILURO-DEVONIANO, 1: Estratigrafia e Paleontologia, 1996, Ponta Grossa. Anais... Ponta Grossa, Universidade Federal do Paraná, Universidade Estadual de Ponta Grossa, pp. 193-218, 1996.

ISAACSON, P. E., PERRY, D. G. Biogeography and morphological conservatism of Tropidoleptus (Brachiopoda, Orthida) during the the Devonian. Journal of Paleontology, v. 51, n. 6, pp. 1108-1122, 1977.

ISAACSON, P. E., SABLOCK, P. E. Devonian paleogeography and palaeobiogeography of the Central Andes. Memoir Geological Society of London, v. 12, pp. 431-435, 1990.

ISAACSON, P. E., MARTINEZ, E. D. Evolução paleogeografica del Paleozoico Medio y Superior de los Andes centrales $\left(14^{\circ}\right.$ a $\left.18^{\circ} \mathrm{S}\right)$ en Bolivia: evidencia del desplazmiento latitudinal de una cuenca de antepais. Revista Técnica de PFB, v. 15, n. 3-4, pp. 265-282, 1994.

JELL, P., THERON, J. Early Devonian echinoderms from South Africa. Memoirs of the Qeensland Museum, v. 43, n. 1, pp. 115-199, 1999.

KAMMER, T. W. Phenotipic bradytely in the Costalocrinus-Barycrinus lineage of Paleozoic cladid crinoids. Journal of Paleontology, v. 75, n. 2, pp. 383-389, 2001.

KAMMER, T. W., AUSICH, W. I. Primitive cladid crinoids from Upper Osagean-Lower Meramecian (Mississippian) rocks of east-central United States. Journal of Paleontology, v. 70, n. 5, pp. 835-866, 1996.

KAMMER, T. W., GAHN, F. J. Primitive cladid crinoids from the early Osagean Burlington Limestone and the phylogenetics of mississippian species of Cyathocrinites. Journal of Paleontology, v. 77, n. 1, pp. 121-138, 2003.

KATZER, F. Geologia do Estado do Pará. Boletim do Museu Paraense Emílio Goeldi de História Natural e Etnografia, v. 9, pp. 1-269, 1933. (Tradução frei Hugo Mense, do original alemão: KATZER, F., 1903. Grundzüge der Geologie Unteren Amazonasgebietes).

KIRK, E. Crinoidea. In: CLARKE, J. M. Fósseis Devonianos do Paraná. Rio de Janeiro: Serviço Geológico e Mineralógico do Brasil, Monografia 1, 353 p., 1913.

KNOD, R. Devonische Faunen Boliviens. Neues Jahrbuch für Mineralogie, Geologie und Paläontologie, v. 25, pp. 493-600, 1908.

LANGE, F.W. Novos fósseis Devonianos do Paraná. Arquivos do Museu Paranaense, v. 3, n. 8, pp. 215-231, 1943.

LE MENN, J. Les crinoïdes du Dévonien Inférieur et Moyen du Massif Armoricain: systématique, paléobiologie, evolution, paléoécologie, biostratigraphie. Mém. Soc. Gól. Minéral. Bretagne, v. 30, pp. 1-268, 1985.

LEMENN,J.CrinoïdesDevoniensd'AfiqueduNord:Revisionsstematiqueetaffinitespaleobiogeographiques. Annales de Societé Géologique du Nord, v .5, pp. 129-140, 1997a.

LE MENN, J. Crinoïdes. In: BOUMENDJELL, K.; BRICE, D.; COPPER, P.; GOURVENNEC, R.; JAHNKE, H.; LAURDEX, H.; Le MENN, J.; MELOU, M.; MORZADEC, P.; PARIS, F.; PLUSQUELLEC, Y., RACHEBOEUF, P. Les Faunes du Dévonien de l'Ougarta (Sahara Occidental, Algérie). Annales de Societé Géologique du Nord, v. 5, pp. 113-114, 1997b.

LE MENN, J., REGNAULT, S. Découverte de microcrinoïdes dans le Dévonien inférieur Du Maroc. C. R. Aca. Sci. Paris, v. 316, n. 2, pp. 251-256, 1993.

MACURDA, D. B. The Devonian blastoids of Bolivia. Journal of Paleontology, v. 53, n. 6, pp.1361-1373, 1979.

McINTOSH, G. C. Apurocrinus sucrei, a new genus and species of camerate crinoid from the Lower Devonian of Bolivia. Journal of Paleontology, v. 55, n. 5, pp. 948-952, 1981.

McINTOSH, J. C. Nuxocrinus e Pyrenocrinus, two new Devonian cladid inadunate crinoid genera. Journal of Paleontology, v. 57, n. 3, pp. 495-513, 1983.

McINTOSH, G. C. Devonian Cladid Inadunate Crinoids: Family Botryocrinidae Bather, 1899. Journal of Paleontology, v. 58, n. 5, pp. 1260-1281, 1984. 
McINTOSH, G. C. Rewiew of the Devonian camerate crinoid Bogotacrinus scheibei Schimdt from Colombia. Journal of Paleontology, v. 61, n. 4, pp. 750-757, 1987.

McINTOSH, G. C. Boliviacrinus isaacsoni, a new genus and species of Middle Devonian camerate crinoid from Bolivia. Journal of Paleontology, v. 62, n. 4, pp. 622-626, 1988.

MELO, J. H. G. The Malvinokaffric Realm in the Devonian of Brazil. In: MCMILLAN, N. J.; EMBRY, A. F. \& GLASS, D. J. (eds.), II INTERNATIONAL SYMPOSIUM ON THE DEVONIAN SYSTEM, 1988, Calgary. Proceedings Calgary, Canada: Canadian Society of Petroleum Geologists, v. 1 (Regional Syntheses), pp. 669703, 1988.

MILANI, E. J., MELO, J. H. G., SOUZA, P. A., FERNANDES, L. A., FRANÇA, A. B. Bacia do Paraná. Boletim de Geociências da Petrobrás, v. 15, n. 2, pp. 265-287, 2007.

MOORE, R. C.; LANE, N. G. \& STRIMPLE, H. L. Cladida. In: MOORE, R. C. \& TEICHERT, C. (eds.) Treatise on Invertebrate Paleontology. Lawrence: The University of Kansas Printing Service, Part T, Echinodermata 2, v. 2, pp. 578-759, 1978.

MORZADEC, P.; PARIS, F.; PLUSQUELLEC, Y.; RACHEBOEUF, P.; WEYANT, M. Devonian stratigraphy and paleogeography of the Armorican Massif (NW France). In: MCMILAN, N. J., EMBRY, A. F., GLASS, D. J. (eds.). Devonian of the world. Proceedings of the SECOND INTERNATIONAL SYMPOSIUM ON THE DEVONIAN SYSTEM, Calgary, Canadian Society of petroleum geologists, Memoir 14, n. 1, pp. 401-420, 1988.

PLUSQUELLEC, Y., BOUMENDJEL, K., MORZADEC, P., PARIS, F. Les faunes dévoniennes d'Ougarta Dans la paléogéografphie des régions Maghrébo-Européennes. Ann. Soc. Géol. Du Nord, v. 5, n. 20, pp.123-128, 1997.

RACHEBOEUF, P. R. ; FARJAT, A. D., LEFEBVRE, B. The Devonian Famoneda Section of Southern Bolivia : new biostratigraphical and palaeobiogeographical data. Revista Española de Paleontologia, v. 13, n. 2, pp. 175-186, 1998.

ROBARDET, M. The Armorica 'microplate': fact or fiction? Critical review of the concept and contradictory palaeobiogeographical data. Palaeogeography, Palaeoclimatology, Palaeoecology, v. 195, n. 125-148, 2003.

SALTER, J. W. Description of Paleozoic Crustacea and Radiata from South Africa. Transactions of the Geological Society of London, v. 7, pp. 215-224, 1856.

SCHEFFLER, S. M. Colunais e pluricolunais dissociadas de Crinoidea da Formação Ponta Grossa (Devoniano, Bacia do Paraná), no Estado do Paraná, Brasil. In: PALEO 2003 - PR/SC, 2004, Mafra/Rio Negro. Porto Alegre: Paleontologia em Destaque, Sociedade Brasileira de Paleontologia, v. 18, p. 41-41 2004a.

SCHEFFLER, S.M. Os crinoides e blastóides da Formação Ponta Grossa (Devoniano, Bacia do Paraná), Estado do Paraná, Brasil. Dissertação de Mestrado. Programa de Pós-Graduação em Geologia - Instituto de Geociências, Universidade Federal do Rio de Janeiro, Rio de Janeiro, 218 p., $2004 b$.

SCHEFFLER, S. M. Equinodermas da Formação Ponta Grossa (Devoniano: Bacia do Paraná): grupos conhecidos e perspectivas futuras. In: CARVALHO, I. S.; CASSAB, R. C. T.; SCHWANKE, C.; CARVALHO, M. A.; FERNANDES, A. C. S.; RODRIGUES, M. A. C.; CARVALHO M. S. S.; ARAI. M., OLIVEIRA, M. E. Q. (org.). Paleontologia: cenários da vida. $1^{a}$ ed. Rio de Janeiro: Interciência, v. 1, pp. 157-166, 2007.

SCHEFFLER, S. M. Morfotipos de pedúnculo de pelmatozoários da Formação Ponta Grossa (Devoniano, Bacia do Paraná), no Estado do Paraná, Brasil. Revista Terr@ Plural, v. 1, pp.139-151, 2008.

SCHEFFLER, S.M. Crinoides e blastoides do Devoniano brasileiro. 2010. Tese de Doutorado - Programa de Pós-Graduação em Geologia, Instituto de Geociências, Universidade Federal do Rio de Janeiro, Rio de Janeiro, $278 \mathrm{p}$.

SCHEFFLER, S. M.; BOLZON, R. T., AZEVEDO, I. Cálices de Crinoidea na Formação Ponta Grossa (Devoniano), Estado do Paraná, Brasil. In: PALEO 2001, ENCONTRO REGIONAL DE PALEONTOLOGIA do PR/SC, Mafra (SC) e Rio Negro (PR), 2001. Programação e Resumos. Mafra e Rio Negro: Universidade do Contestado, p. 11, 2001.

SCHEFFLER, S. M.; BOLZON, R. T., AZEVEDO, I. Análise morfológica dos crinóides do afloramento Rio Caniú (Formação Ponta Grossa), Estado do Paraná, Brasil. Acta Geologica Leopoldensia, v. 25, n. 54, pp. 65-76, 2002. 
SCHEFFLER, S. M., FERNANDES, A. C. S. Ocorrência de cálice de crinoide, Formação Ponta Grossa (Devoniano, Bacia do Paraná), Estado do Paraná. In: XVII CONGRESSO BRASILERO DE PALEONTOLOGIA, 17, Brasília. Boletim de Resumos... Brasília, Sociedade Brasileira de Paleontologia, pp. 258-259, 2003.

SCHEFFLER, S. M., FERNANDES, A. C. S. Crinoidea da Formação Ponta Grossa (Devoniano, Bacia do Paraná), Brasil. Arquivos do Museu Nacional, v. 65, n.1, pp. 83-98, 2007a.

SCHEFFLER, S. M., FERNANDES, A. C. S. Blastoidea da Formação Ponta Grossa (Devoniano, Bacia do Paraná), Brasil. Arquivos do Museu Nacional, v. 65, n. 1, pp. 99-112, $2007 \mathrm{~b}$.

SCHEFFLER, S. M.; FERNANDES, A. C. S., FONSECA, V. M. M. Crinoidea da Formação Maecuru (Devoniano da Bacia Do Amazonas), Estado do Pará, Brasil. Revista Brasileira de Paleontologia, v. 9, n. 2, pp. 235-242, 2006.

SCHEFFLER, S.M., SILVA, S.D., GAMA JÚNIOR, J.M., FONSECA, V.M.M., FERNANDES, A.C.S. Middle Devonian crinoids from the Parnaiba Basin (Pimenteira Formation, Tocantins State, Brazil). Journal of Paleontology, v. 85, n. 6, pp. 1188-1198, 2011.

SCHEFFLER, S. M.; FERNANDES, A. C. S. F.; FONSECA, V. M. M. Crinoidea da Formação Ererê (Eifeliano Tardio - Givetiano Inicial, Bacia do Amazonas, Estado do Pará, Brasil). Journal of South American Earth Sciences, 2013.

SCHMIDT, W. Die Crinoïdeen des Rheinischen Devons. II. Die Crinoïdeen des Unterdevons bis zur Cultrijugaltus-Zone (mit Asschluss des Hunsrückschiefers. Abhandlungen der Reichsstelle für Bodenforschung, v.182, pp.1-253, 1941.

SCOTESE, C. R., MCKERROW, W. S. Revised world maps and introduction. In: MCKERROW, W. S., SCOTESE, C. R. (eds.) Palaeozoic palaeogeography and biogeography. The Geological Society Memoir, v. 12, pp.1-21, 1990.

SÜDKAMP, W. H. Name change for the diplobathrid camerate crinoids Acanthocrinus spinosus Su"dkamp 2007 from the lower Devonian Hunsru“ck Slate (Germany). Pala“ontol Z, p. 1-4, 2013.

THOMPSON, J. R; AUSICH, W. I.; SMITH, L. Echinoderms from the Lower Devonian (Emsian) of Bolivia (Malvinokaffric Realm). Journal of Paleontology, v. 87, n. 1, pp. 166-175, 2013.

TROTH, I., JOHN, E.A. M., RACEY, A. R. BECKER, T. Devonian sea-level change in Bolivia: A high palaeolatitude biostratigraphical calibration of the global sea-level curve. Palaeogeography, Palaeoclimatology, Palaeoecology, v. 304, pp. 3-20, 2011.

UBAGHS, G. Skeletal morphology of fossil crinoids. In: MOORE, R. C. \& TEICHERT, C. (eds.) Treatise on Invertebrate Paleontology. Lawrence: The University of Kansas Printing Service, Part T, Echinodermata 2, v. 1, pp. 58-216, 1978a.

UBAGHS, G. Camerata. In: MOORE, R. C., TEICHERT, C. (eds.) Treatise on Invertebrate Paleontology. Lawrence: The University of Kansas Printing Service, Part T, Echinodermata 2, v. 2, pp. 408-519, 1978b.

ULRICH, A. Palaeozoische Versteinerungen aus Bolivien. Neues Jahrbuch für Mineralogie. Geologie und Paläontologie, v. 8, pp. 5-116, 1892.

VAN SANT, J. F., LANE, N. G. Crawfordsville (Indiana) crinoid studies. University of Kansas Paleontological Contribution, v. 7, pp. 1-136, 1964.

WAISFELD, B. G. Comunidad de Bridgerocrinus (Crinoidea:Scytalocrinidae) en la Formacion Talàcasto (Devonico) de la precordillera de San Juan, Argentina. Ameghiniana, v. 25, n. 3, pp. 273-279, 1989.

WEBSTER, G. D. Paleobiogeography of Devonian and Carboniferous crinoide faunas of Gondwana. Records of the western Australian Museum, Suppl. 58, pp. 403-420, 2000.

Recebido em 11/10/2013

Aceito para publicação em 02/12/2013 
